\title{
ATIVIDADES DE SUPERÓXIDO DISMUTASE, CATALASES E PEROXIDASE DURANTE O DESENVOLVIMENTO DE MICORRIZAS ARBUSCULARES EM FEIJOEIRO, SOB CONDIÇÕES DE BAIXO E ALTO NÍVEL DE FOSFATO
}

WINSTON FRANZ RÍOS RUIZ

Biólogo

Orientador: Prof. Dr. MARCIO RODRIGUES LAMBAIS

Dissertação apresentada à Escola Superior de Agricultura "Luiz de Queiroz", Universidade de São Paulo. para obtenção do título de Mestre em Agronomia. Área de concentração: Microbiologia Agrícola.

P I R A C I C A B A

Estado de São Paulo - Brasil

Novembro - 1998 
Dados Internacionais de Catalogação na Publicação (CIP) DIVISÃo DE BIBLIOTECA E DOCUMENTAÇÃO - Campus "Luiz de Queiroz"/USP

\section{Rios Ruiz, Winston Franz}

Atividade de superóxido dismutase, catalases e peroxidase durante 0

desenvolvimento de micorrizas arbusculares em feijoeiro, sob condiçōes de baixo e alto nivel de fosfato / Winston Franz Ríos Ruiz. - - Piracicaba, 1998.

50 p. : il.

Dissertação (mestrado) - - Escola Superior de Agricultura Luiz de Queiroz, 1998. Bibliografia.

1. Catalase 2. Enzima 3. Feijão 4. Fosfato no solo 5. Micorriza 6. Peroxidase 7. Raiz 8. Superóxido dismutase 9 . Simbiose I. Título 
Aos meus pais,

Josias e Luzdina

OFEREÇO

À minha esposa, Beatriz Aos meus filhos, Natalie e Franz DEDICO 


\section{AGRADECIMENTOS}

Ao Prof. Dr. Marcio Rodrigues Lambais do Departamento de Ciência do SoloESALQ/USP, pela orientação, amizade e apoio em todos os momentos;

A todo o Corpo Docente e demais funcionários dos Departamentos da ESALQ/USP, que propiciaram minha formação acadêmica em Microbiologia Agrícola;

Ao Prof. Dr. Luiz Gonzaga do Prado Filho pela oportunidade para a realização de meus estudos.

À coordenação do curso de pós-graduação em Agronomia: Microbiologia Agrícola, representada pelo Prof. Dr. Flávio Cesar Almeida Tavares, pela atenção e colaboração no decorrer do curso;

Ao Prof. Dr. Ricardo Azevedo, pelas valiosas sugestões;

Aos técnicos do laboratório de Microbiologia do Solo, Denise e Fernando, pelo auxílio e amizade;

Aos colegas do laboratório de Microbiologia do Solo (Adriana, Ângela, Beatriz, Elizabeth, Cleide, Heron, Leandra, Lúcia, Marcelo, Marcio, Marco, Milene, Ozinaldo, Paulo, Renata e Robinson), pelo companheirismo e colaboração;

Aos meus pais, Josias e Luzdina, e irmãos, Luz, Ofelia, Carlos, Digna, Tedy, Raul, Rolando, Waldo, Walter e Maria Milagro, pela confiança e incentivo;

À minha esposa, Beatriz, e aos meus filhos, Natalie e Franz, por criar esperança nos momentos mais dificeis;

A Beto e Keila, amigos do laboratório de Genética de Leveduras, e à Salete do laboratório de Bioquímica de Plantas do Departamento de Genética, pelo auxílio e apoio nas análises laboratoriais;

À Fundação de Amparo à Pesquisa do Estado de São Paulo, pelo auxílio financeiro fornecido (Processo: 96/08057-4);

À Deus, que sempre orientou meus passos. 


\section{SUMÁRIO}

Página

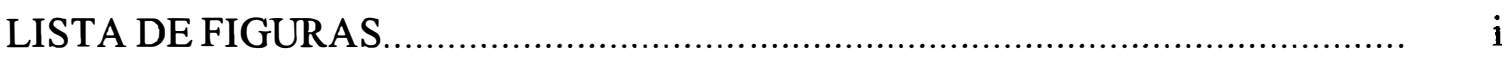

LISTA DE TABELAS ........................................................................... iv

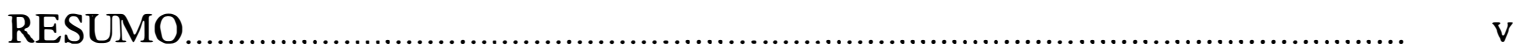

SUMMARY

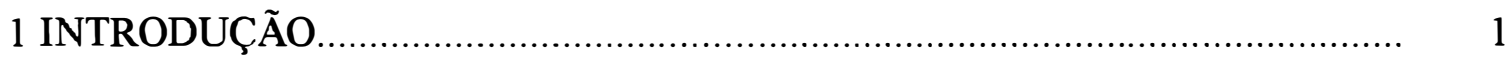

2 REVISÃO DE LITERATURA.............................................................. 3 ,

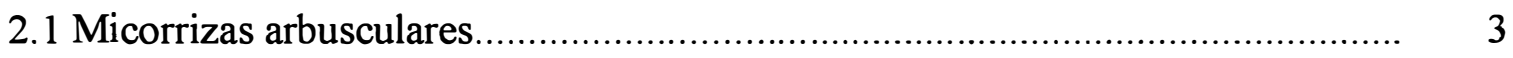

2.2 Mecanismos de defesa em interações planta-microrganismos......................... 4

2.3 Expressão de genes de defesa em micorrizas arbusculares.............................. 6

$2.4 \mathrm{O}$ fósforo e sua relação com micorrizas arbusculares..................................... 7

2.5 Espécies ativas de oxigênio e a explosão oxidativa..................................... 8

2.5.1 Química das espécies ativas de oxigênio................................................. 8

2.5.2 Transdução de sinais na explosão oxidativa................................................ 9

2.5.3 Funções da explosão oxidativa............................................................ 12

2.5.4 Mecanismos de remoção das espécies ativas de oxigênio............................ 13

2.6 Superóxido dismutases...................................................................... 13

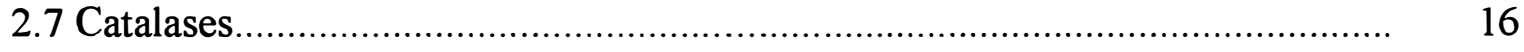

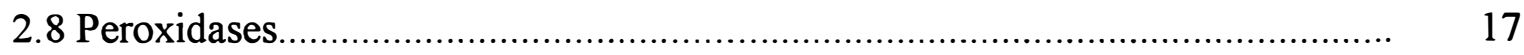

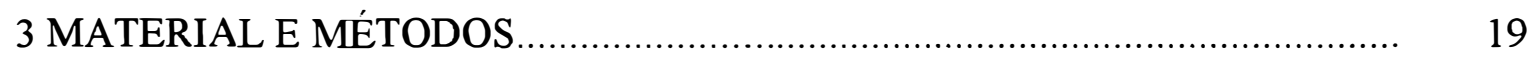

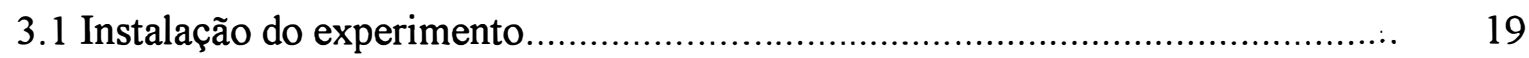

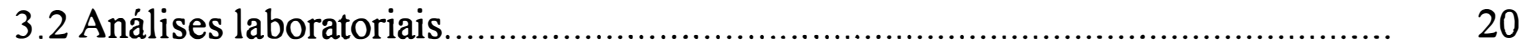

3.2.1 Obtenção das raizes de feijão e avaliação do nivel de colonização................. 20 


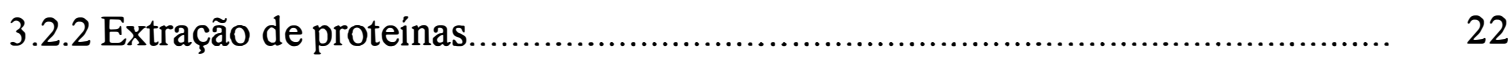

3.2.3 Determinação do conteúdo total de proteínas............................................... 24

3.2.4 Determinação das atividades de superóxido dismutase.................................... 24

3.2.5 Determinação das atividades de catalases..................................................... 25

3.2.6 Caracterização isoenzimática de catalases em géis de poliacrilamida............ 25

3.2.7 Determinação das atividades de peroxidase.................................................... 26

4 RESULTADOS E DISCUSSÃO............................................................... 28

4.1 Crescimento das plantas e colonização radicular............................................. 28

4.2 Atividades enzimáticas de superóxido dismutase ......................................... 32

4.3 Atividades enzimáticas e caracterização isoenzimática de catalases................. 34

4.5 Atividades enzimáticas de peroxidase ...................................................... 38

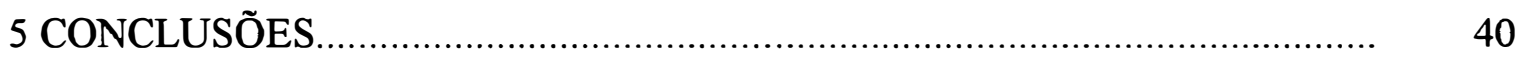

REFERÊNCIAS BIBLIOGRÁFICAS............................................................... 41 


\section{LISTA DE FIGURAS}

Página

1 Modelo hipotético para a sinalização e transdução de sinais envolvendo espécies ativas de oxigênio (EAOs) em interações planta-patógenos. A ativação de genes de defesa resulta em reação de hipersensibilidade (RH) (Leite et al., 1997)

2 Vista geral das plantas de feijoeiro na casa-de-vegetação, aos 55 dias após transplantio

3 Aspectos morfológicos de micorrizas arbusculares em raizes de feijoeiro colonizadas por G. clarum. A: seta superior, vesícula; seta inferior, hifa. B: seta superior, hifa; seta inferior, arbúsculo.

4 Porcentagem de colonização de raízes de feijoeiro inoculadas com $G$. intraradices ou G. clarum, em condições de baixo (20 mg P kg ${ }^{-1}$ ) ou alto (150 $\mathrm{mg} \mathrm{P} \mathrm{kg}^{-1}$ ) nível de fosfato. As determinações foram realizadas 4, 6, 8 e 10 semanas após a inoculação.

5 Atividades específicas de superóxido dismutases em raízes de feijoeiro não-inoculadas ou inoculadas com $G$. intraradices ou $G$. clarum, em condições de baixo (20 mg $\mathrm{P} \mathrm{kg}^{-1}$ ) ou alto (150 $\mathrm{mg} \mathrm{P} \mathrm{kg}^{-1}$ ) nível de fosfato. As atividades foram determinadas 4, 6, 8 e 10 semanas após a inoculação. Os dados são médias de 4 repetições \pm desvio padrão da média. *, diferença significativa (teste $t, \mathrm{p}<0,05$ ), em relação ao controle não-inoculado, na mesma época de amostragem. 
6 Atividades específicas de catalases em raízes de feijoeiro não-inoculadas ou inoculadas com G. intraradices ou G. clarum, em condições de baixo (20 $\mathrm{mg} \mathrm{P} \mathrm{kg}^{-1}$ ) ou alto (150 $\mathrm{mg} \mathrm{P} \mathrm{kg}^{-1}$ ) nível de fosfato. As atividades foram determinadas 4, 6, 8 e 10 semanas após a inoculação. Os dados são médias de 4 repetições \pm desvio padrão da média. *, diferença significativa (teste $t, \mathrm{p}<0,05$ ), em relação ao controle não-inoculado, na mesma época de amostragem.

7 Caracterização isoenzimática de catalases em gel de poliacrilamida nãodesnaturante. A eletroforese foi realizada com quantidades iguais de proteína total $(30 \mu \mathrm{g})$ de raizes de feijoeiro não-inoculadas $(\mathrm{Ni})$ ou inoculadas por G. intraradices (Gi) ou G. clarum (Gc), em condições de baixo ( $\left.\mathrm{BP}=20 \mathrm{mg} \mathrm{P} \mathrm{kg}^{-1}\right)$ ou alto $\left(\mathrm{AP}=150 \mathrm{mg} \mathrm{P} \mathrm{kg}^{-1}\right)$ nível de fosfato. $\mathrm{SAI}$, semanas após inoculação; $\mathrm{C}$, controle positivo (duas unidades de catalase de figado de boi)

8 Atividades específicas de peroxidases em raizes de feijoeiro nãoinoculadas ou inoculadas com G. intraradices ou G. clarum, em condições de baixo (20 mg P kg${ }^{-1}$ ) ou alto (150 $\mathrm{mg} \mathrm{P} \mathrm{kg}^{-1}$ ) nível de fosfato. As atividades foram determinadas 4, 6, 8 e 10 semanas após a inoculação. Os dados são médias de 4 repetições \pm desvio padrão da média. *, diferença significativa (teste $t, \mathrm{p}<0,05$ ), em relação ao controle não-inoculado, na mesma época de amostragem 


\section{LISTA DE TABELAS}

página

1 Massa de matéria fresca do sistema radicular (MFSR) e massa de matéria seca da parte aérea (MSPA) de plantas de feijão não-inoculadas ou inoculadas por $G$. intraradices ou $G$. clarum, em condições de baixo (20 $\mathrm{mg} \mathrm{P} \mathrm{kg}^{-1}$ ) ou alto (150 $\mathrm{mg} \mathrm{P} \mathrm{kg}^{-1}$ ) nível de fosfato. As amostras foram coletadas 4, 6, 8 e 10 semanas após a inoculação. 


\title{
ATIVIDADES DE SUPERÓXIDO DISMUTASE, CATALASES E PEROXIDASE DURANTE O DESENVOLVIMENTO DE MICORRIZAS ARBUSCULARES EM FEIJOEIRO, SOB CONDIÇÕES DE BAIXO E ALTO NÍVEL DE FOSFATO
}

\author{
Autor: WINSTON FRANZ RÍOS RUIZ \\ Orientador: Prof. Dr. MARCIO RODRIGUES LAMBAIS
}

\section{RESUMO}

Durante a colonização de tecidos vegetais por microrganismos patogênicos, espécies ativas de oxigênio são geradas e podem levar à indução da expressão de genes relacionados ao sistema de defesa vegetal. Existem evidências mostrando que compostos como $\mathrm{H}_{2} \mathrm{O}_{2}$ funcionam como mensageiros secundários no processo de transmissão de sinais entre os microrganismos e as plantas, e poderiam estar envolvidos também na regulação do desenvolvimento de micorrizas arbusculares.

Nesse trabalho foram avaliadas as atividades de superóxido dismutase (SOD), catalases (CAT) e peroxidase (POX) em raizes de feijoeiro inoculadas com Glomus intraradices ou Glomus clarum, sob condições de baixo ou alto nível de fosfato $(\mathrm{P})$ no solo. $\mathrm{O}$ ensaio foi conduzido em casa-de-vegetação e as plantas foram colhidas $4,6,8$, e 10 semanas após a inoculação (SAI).

G. clarum apresentou maior infectividade (capacidade de colonização radicular), comparado com $G$. intraradices. As maiores taxas de colonização radicular foram obtidas $10 \mathrm{SAI}$. Nessa época de amostragem, a colonização por G. clarum foi de $76 \%$ em condições de baixo $\mathrm{P}$ e de $28 \%$ em condições de alto $\mathrm{P}$, enquanto que por $G$. intraradices foi de $6 \%$ e $3 \%$, respectivamente.

Em raizes colonizadas por $G$. clarum, as atividades de SOD, em condições de baixo $\mathrm{P}$ no solo, foram $63 \%$ maiores do que em raizes do controle não-inoculado, 10 SAI; enquanto que, em condições de alto $\mathrm{P}$, as atividades de SOD só diferiram 
significativamente do controle não-inoculado no início do desenvolvimento da simbiose (4 SAI).

Induções significativas das atividades de CAT foram observadas em raízes colonizadas por $G$. clarum, sob condições de baixo P, 4, 6 e $10 \mathrm{SAI}$, em relação ao controle não-inoculado, já em condições de alto $\mathrm{P}$, induções significativas só foram observadas 4 SAI. Supressão das atividades de CAT, em relação ao controle não inoculado, foi observada em raízes colonizadas por G. clarum, sob alto P, 8 SAI. Através da caracterização isoenzimática em gel de poliacrilamida não-desnaturante, observou-se a presença de uma única isoforma de CAT nos diferentes tratamentos.

Em condições de baixo $\mathrm{P}$, as atividades de $\mathrm{POX}$ em raízes colonizadas por $G$. clarum foram $136 \%$ maiores e 58\% menores do que em raízes do controle nãoinoculado, 4 e $10 \mathrm{SAI}$, respectivamente. Supressão significativa das atividades de POX sob condições de alto $\mathrm{P}$ só foram observadas em raízes colonizadas, $10 \mathrm{SAI}$.

As atividades de SOD, CAT e POX em raízes colonizadas pelo fungo menos infectivo, G. intraradices, não diferiram significativamente em nenhuma das épocas de amostragem, em relação aos controles não-inoculados.

Os dados obtidos sugerem que durante o desenvolvimento de micorrizas arbusculares, catalases poderiam estar participando da degradação de $\mathrm{H}_{2} \mathrm{O}_{2}$, evitando seu acúmulo e a possível ativação de genes de defesa e facilitando, assim, o crescimento fúngico intrarradicular. 


\title{
SUPEROXIDE DISMUTASE, CATALASE AND PEROXIDASE ACTIVITIES \\ DURING THE DEVELOPMENT OF ARBUSCULAR MYCORRHIZAE IN BEAN ROOTS UNDER LOW AND HIGH PHOSPHATE CONDITONS
}

\author{
Author: WINSTON FRANZ RÍOS RUIZ \\ Adviser: Prof. Dr. MARCIO RODRIGUES LAMBAIS
}

\section{SUMMARY}

During colonization of plant tissues by pathogenic microorganisms, the accumulation of reactive oxygen species may lead to the induction of plant defense related genes. It has been shown that $\mathrm{H}_{2} \mathrm{O}_{2}$ may be involved in the signal transduction leading to defense gene activation and might as well be involved in the control of arbuscular mycorrhizal growth and development.

In this work, the activities of superoxide dismutase (SOD), catalase (CAT) and peroxidase (POX) were evaluated during the development of arbuscular mycorrhizae in bean roots inoculated with Glomus clarum or Glomus intraradices, under low and high P conditions. Plants were harvested at 4, 6, 8 and 10 weeks after inoculation (WAI).

G. clarum presented a higher infectivity (root colonization capability) as compared to $G$. intraradices. The highest colonization rates were observed $10 \mathrm{WAI}$. At this sampling time, root colonization by $G$. clarum under low $\mathrm{P}$ conditions was $76 \%$, and $28 \%$ under high $\mathrm{P}$, whereas colonization by $G$. intraradices was $6 \%$ and $3 \%$, respectively.

SOD activities were $63 \%$ higher in root colonized by $G$. clarum than in notinoculated controls, at $10 \mathrm{WAI}$, under low $\mathrm{P}$ conditions, whereas under high $\mathrm{P}$, significant differences were observed only at $4 \mathrm{WAI}$.

Significant inductions of CAT activities were observed in roots colonized by $G$. clarum under low P conditions at 4, 6 and $10 \mathrm{WAI}$, compared to not-inoculated controls. Under high $\mathrm{P}$, significant induction of CAT activities was observed in roots inoculated 
with G. clarum, at 4 WAI. Significant suppression of CAT activities were observed in roots colonized by $G$. clarum under high $\mathrm{P}$ conditions at $8 \mathrm{WAI}$, compared to notinoculated controls. Isoenzymatic characterization of CATs in non-denaturing polyacrilamyde gel electrophoresis showed the presence of one isoform in the different treatments.

POX activities in roots colonized by G. clarum were $136 \%$ higher and 58\% lower than in not-inoculated control roots, at 4 and $10 \mathrm{WAI}$, respectively. Significant suppression under high $\mathrm{P}$, was observed only at 10 weeks after inoculation with $G$. clarum.

The activities of SOD, CAT and POX in roots colonized by the less infective fungus, G. intraradices, were not significantly different from not-inoculated controls at all harvests.

The data suggest that, during arbuscular mycorrhizae development, $\mathrm{H}_{2} \mathrm{O}_{2}$ might be degraded by catalases in the roots, avoiding the activation of plant defense related genes involved in the control of intraradical fungal growth. 


\section{INTRODUÇÃO}

Micorrizas arbusculares (MAs) são associações mutualísticas biotróficas entre fungos da ordem Glomales e a maioria das plantas vasculares. Esta associação é de ocorrência bastante generalizada e apresenta grande importância nos diversos agrossistemas e ecossistemas naturais. Os efeitos benéficos da associação para o crescimento das plantas resultam principalmente do aumento na absorção e utilização de nutrientes minerais, em especial do fósforo, em solos de baixa fertilidade (Harley \& Smith, 1983). O processo de colonização das raízes pelos fungos micorrízicos arbusculares (FMAs) envolve uma série de eventos morfo-fisiológicos, os quais são regulados pelo genoma do fungo e da planta, bem como por fatores ambientais (Gianinazzi-Pearson, 1995).

As bases moleculares do processo de colonização e os mecanismos que controlam o desenvolvimento de MAs são ainda desconhecidos. Porém, existem evidências de que a regulação diferencial do sistema de defesa vegetal poderia determinar, pelo menos em parte, o padrão de crescimento fúngico intrarradicular. Apesar de FMAs colonizarem extensivamente o tecido cortical das raízes, a ativação do sistema de defesa vegetal é limitada, transiente e pode ocorrer somente em células específicas (Lambais \& Mehdy, 1995; Lambais, 1996).

Durante a colonização de tecidos vegetais por microrganismos patogênicos, espécies ativas de oxigênio (EAOs) são geradas e podem levar à indução ou supressão da expressão de genes relacionados ao sistema de defesa. Existem evidências mostrando que compostos como $\mathrm{H}_{2} \mathrm{O}_{2}$ funcionam como mensageiros secundários no processo de transmissão de sinais em interações planta-microrganismos (Sharma, 1992; Tenhaken et al., 1995), e poderiam estar envolvidos também na regulação de MAs. Assim em MAs, 
uma interação "compatível de longa duração" (Lambais \& Mehdy, 1995), a concentração de EAOs poderia ser estritamente regulada através da ação de enzimas antioxidantes como catalases (CATs), superóxido dismutases (SODs), ou peroxidases (POXs), evitando uma explosão oxidativa e a ativação de genes de defesa vegetal.

Quando a condição ambiental é favorável ao desenvolvimento das MAs (baixo nível de fosfato, por exemplo), a ação de enzimas antioxidantes seria maximizada, devido à ação direta de algum composto de origem fúngica ou vegetal produzido durante a formação de micorrizas, ou por alterações da fisiologia da planta hospedeira naquela condição ambiental específica. Nessa condição, não haveria acúmulo de EAOs e nem ativação de genes de defesa. Alternativamente, em condições desfavoráveis ao desenvolvimento das MAs (alto nível de fosfato, por exemplo), enzimas antioxidantes teriam sua expressão suprimida, levando ao acúmulo de EAOs e indução de genes de defesa a níveis capazes de reduzir o crescimento fúngico, sem, no entanto, resultar em resposta de hipersensibilidade (RH). Assim, o estudo da expressão desses genes em MAs, em condições favoráveis e desfavoráveis ao seu desenvolvimento, seria fundamental para o entendimento de como os FMAs colonizam o córtex das raízes sem ativar o sistema de defesa vegetal e dos mecanismos pelos quais o fosfato do solo modula a simbiose.

O objetivo do presente trabalho foi determinar a atividade de enzimas envolvidas na geração e degradação de EAOs (SODs, CATs, e POXs) durante o desenvolvimento de MAs em raízes de feijão inoculadas com Glomus intraradices ou Glomus clarum, em condições de baixo e alto nível de fosfato no solo. 


\section{REVISÃO DE LITERATURA}

\subsection{Micorrizas arbusculares}

As MAs representam a simbiose mais freqüente na natureza e as que apresentam o maior potencial para aplicação agrícola. Como as MAs ocorrem na maioria das plantas de interesse econômico (Koide \& Schreiner, 1992; Silveira, 1992; Gianinazzi-Pearson, 1996), sua utilização poderia resultar em reduções significativas dos custos de produção.

As MAs são formadas pela associação simbiótica entre fungos da ordem Glomales (Zigomicetos) e as raizes dos vegetais (Morton \& Benny, 1990; Walker \& Trappe, 1993). Na simbiose, os organismos envolvidos apresentam perfeita integração morfológica e fisiológica, resultando em compatibilidade funcional. Em condições ideais, essas associações são mutualísticas e ambos os simbiontes são beneficiados. A planta hospedeira tem sua nutrição, especialmente em fósforo $(P)$, favorecida e pode apresentar maior tolerância a diversos fatores estressantes. O fungo, por outro lado, obtém fotossintatos do hospedeiro para seu crescimento (Smith \& Smith, 1990). Porém, o balanço entre o dreno de fotossintatos da planta e o aumento da absorção de $\mathrm{P}$ é estritamente controlado, particularmente, pela concentração de P na planta (Siqueira \& Colozzi-Filho, 1986; Lambais, 1996).

O processo de colonização pelos FMAs inicia-se com o contato entre uma hifa originária de um propágulo, que pode ser um esporo, fragmento de raiz colonizada ou segmentos de hifas existentes no solo, e a raiz do vegetal. Segue-se um crescimento profuso das hifas ao redor das raizes, até a diferenciação do apressório sobre a superficie radicular. Em plantas hospedeiras, o apressório pode ser formado sobre uma célula ou entre duas células epidérmicas adjacentes. Em plantas não-hospedeiras ou em mutantes 
defectivos na capacidade de formar micorriza, estruturas semelhantes a apressórios podem ser formadas na superfície das raízes, porém estas não diferenciam-se completamente (Bonfante-Fasolo \& Perotto, 1992; Bonfante \& Perotto, 1995). O crescimento do micélio no interior da raiz restringe-se ao tecido cortical e pode ser tanto inter quanto intracelular. Porções terminais ou intercalares da hifa intrarradicular podem diferenciar-se em vesículas, às quais são atribuídas funções de reserva, uma vez que acumulam grande quantidade de lipídios. Hifas intracelulares da camada mais interna do córtex sofrem repetidas ramificações dicotômicas, formando sistemas complexos de hifas ramificadas, denominados arbúsculos. Estas estruturas permanecem envoltas pela plasmalema intacta do hospedeiro, e constituem os sítios preferenciais de troca de metabólitos entre os simbiontes. Os arbúsculos tem período funcional entre 4 e 15 dias, e após sua degeneração, a célula hospedeira volta à sua atividade normal. De forma simultânea ao crescimento intrarradicular do fungo, a proliferação do micélio extrarradicular pode gerar novos pontos de infecção e expandir a colonização (BonfanteFasolo \& Perotto, 1992). Esse micélio também ramifica-se além da rizosfera, ampliando o volume do solo explorado pelas raízes.

Uma das características mais marcantes dos FMAs, é a incapacidade de desenvolverem-se na ausência da planta hospedeira (biotróficos obrigatórios). Esta propriedade é um dos principais fatores que impedem maiores avanços no estudo da fisiologia destes fungos e da associação micorrízica (Bonfante-Fasolo \& Perotto, 1992). Embora a estrutura e organização das MAs sejam conhecidas, os eventos moleculares que determinam como a planta controla a invasão dos fungos, bem como os mecanismos pelos quais as plantas diferenciam o simbionte de um patógeno, ainda não foram elucidados.

\subsection{Mecanismos de defesa em interações planta-microrganismos}

As interações observadas entre plantas e microrganismos podem ser classificadas como incompatíveis e compatíveis (Bowler et al., 1992). Reações incompatíveis (resistência) apresentam desenvolvimento de resposta de hipersensibilidade (RH), a qual 
é caracterizada pelo acúmulo de fitoalexinas e morte celular. A RH restringe o patógeno ao sítio de infecção e impede a colonização das células adjacentes (Mehdy, 1994). Em interações compatíveis, a RH não é observada (suscetibilidade) e o patógeno pode desenvolver-se sem restrições.

A resistência do hospedeiro é caracterizada por sua natureza dinâmica e coordenada. Sua efetividade depende da expressão de genes de defesa em uma seqüência lógica, após o contato do patógeno em potencial com o hospedeiro. Além disso, mostrase como um sistema multicomponente, onde o nível de resistência resulta da somatória das contribuições individuais de diferentes mecanismos de resistência.

Esses mecanismos podem ser divididos em duas categorias (Pascholati \& Leite, 1995; Lucas, 1998):

a) Pré-formados (passivos/constitutivos)

Estruturais: cutícula, tricomas, estômatos, fibras/vasos condutores; Bioquímicos: fenóis, alcalóides glicosídios, lactonas insaturadas, glicosídeos fenólicos e cianogênicos, inibidores protéicos, fitotoxinas, quitinases e $\beta-1,3$ glicanases.

b) Pós-formados (ativos/induziveis)

Estruturais: papilas, halos, lignificação, camadas de cortiça, tiloses;

Bioquímicos: fitoalexinas, proteínas relacionados à patogênese (proteínas-RP) e a explosão oxidativa.

Dependendo do tipo de interação estudada, sinais moleculares são reconhecidos e transmitidos para sítios receptores no hospedeiro, onde são finalmente traduzidos em uma resposta fisiológica. Os mensageiros secundários, que vão transmitir e amplificar o sinal molecular primário e induzir a expressão de genes de defesa local e sistemicamente, bem como seus mecanismos de ação, não são totalmente conhecidos. Sabe-se, no entanto, que a ativação de genes de defesa vegetal resulta no acúmulo de várias enzimas hidrolíticas e proteínas estruturais da parede celular vegetal (Lamb et al., 1989; Bowles, 1990; Leite et al., 1997).

$\mathrm{Na}$ transdução dos sinais moleculares primários pode ocorrer aumento do influxo de $\mathrm{Ca}^{+2}$, mudanças específicas na fosforilação de proteínas, geração de EAO, síntese de 
ácido salicílico e de proteínas-RP (Dangl et al., 1996, Hammond-Kosack \& Jones, 1996; Leite et al., 1997).

\subsection{Expressão de genes de defesa em micorrizas arbusculares}

Apesar da colonização extensiva das raizes pelos FMAs, não há desenvolvimento de sintomas evidentes de RH em MAs, em oposição ao que ocorre em interações plantapatógenos incompatíveis (Gianinazzi, 1991). A ausência de RH é similarmente observada na simbiose entre leguminosas e Rhizobium. Aparentemente, em ambos os sistemas, os simbiontes são reconhecidos pelos hospedeiros de modo a formarem interações compatíveis de longa duração (Lambais \& Mehdy, 1995; Gianinazzi-Pearson et al., 1996).

Os genes envolvidos na defesa vegetal e modulados durante a formação de MAs, podem ser divididos em quatro grupos (Lambais, 1996):

a) Genes envolvidos na via biossintética de fitoalexinas isoflavonóides: fenilalanina amônia liase (FAL), chalcone sintase (CHS), chalcone isomerase ( $\mathrm{CHI})$ e isoflavona redutase (IFR).

b) Genes codificando hidrolases com atividades antimicrobianas: quitinases e $\beta-1,3-$ glicanases.

c) Genes codificando proteínas envolvidas no aumento da rigidez da parede celular vegetal: peroxidases e proteínas ricas em hidroxiprolina (PRHPs).

d) Genes codificando proteínas-RP: RP-b 1 e RP1.

Induções de respostas de defesa podem ser observadas em estágios iniciais do desenvolvimento de MAs e são seguidas de supressão nos estágios mais tardios de colonização intrarradicular, como demonstram os estudos realizados com FAL (Volpin et al., 1994; Mohr et al., 1998), CHI (Volpin et al., 1994), quitinases (Spanu et al., 1989; Lambais \& Mehdy, 1993; Volpin et al., 1994, Vierheilig et al., 1994; Mohr, et al., 1998); ß-1,3-glicanases (Lambais \& Mehdy, 1993; Mohr, et al., 1998), peroxidases (Spanu \& Bonfante-Fasolo, 1988; Fries et al., 1996). A indução das atividades de quitinases e peroxidases foram observadas por Dumas-Gaudot et al. (1992) e McArthur \& Knowles 
(1992), porém, nestes casos não observou-se supressão das atividades dessas enzimas nos estágios tardios.

De maneira geral, a expressão de certos genes relacionados ao sistema de defesa vegetal é localizadamente induzida durante a formação das MAs, enquanto a expressão de outros genes é sistemicamente suprimida, sendo que essa modulação pode depender de fatores externos, como o nivel de $\mathrm{P}$.

\subsection{O fósforo e sua relação com micorrizas arbusculares}

A colonização dos tecidos corticais por FMAs é, aparentemente, um processo controlado e depende das condições ambientais, principalmente da concentração de $P$. Uma forma das plantas regularem a colonização micorrízica seria através do controle da transferência de fotossintatos para o fungo. Esse controle pode se dar pela redução da alocação de carboidratos para o sistema radicular, ou pela diminuição da eficiência de transferência destes para os fungos, através dos arbúsculos. Este mecanismo de controle da colonização micorrízica, no entanto, ainda não está elucidado (Siqueira \& Franco, 1988). A simbiose é mutualística quando o suprimento de nutrientes, particularmente de $\mathrm{P}$, for baixo, ou quando houverem outras condições estressantes que limitem $\mathrm{O}$ crescimento das raízes. No entanto, concentrações muito baixas ou muito altas de $\mathrm{P}$ podem resultar em depressão do crescimento das plantas micorrizadas em relação a plantas não micorrizadas (Siqueira \& Colozzi-Filho, 1986).

Embora os mecanismos envolvidos na regulação da colonização e da eficiência simbiótica pelo $\mathrm{P}$ não sejam conhecidos, existem evidências mostrando que essa regulação depende do status nutricional da parte aérea (Koide \& Li, 1990; Bolan, 1991). Lambais \& Mehdy (1995) sugerem uma hipótese para explicar o mecanismo do controle da simbiose, envolvendo o $\mathrm{P}$, fitormônios e o sistema de defesa vegetal. Alterações no balanço hormonal causadas pela infecção do fungo, assim como por baixos níveis de $\mathrm{P}$ na planta, poderiam resultar na supressão do sistema de defesa vegetal, possibilitando o estabelecimento da interação. De maneira inversa, altos níveis de $\mathrm{P}$ podem aumentar a 
síntese de etileno e, consequentemente, induzir a expressão de certas proteínas-RP, além de outros mecanismos de defesa, impossibilitando o estabelecimento da simbiose.

\subsection{Espécies ativas de oxigênio e a explosão oxidativa}

\subsubsection{Química das espécies ativas de oxigênio}

A atmosfera da terra nos estágios iniciais da evolução biológica era quase desprovida de oxigênio molecular $\left(\mathrm{O}_{2}\right)$ e as primeiras células foram, portanto, anaeróbias. Com o surgimento das células fotossintetizantes, produtoras de $\mathrm{O}_{2}$, a atmosfera terrestre tornou-se progressivamente mais rica em $\mathrm{O}_{2}$, permitindo a evolução dos organismos aeróbios, os quais oxidam compostos orgânicos e tem $\mathrm{O}_{2} \mathrm{O}_{2}$ como aceptor final de elétrons (Scandalios, 1990).

Embora $\mathrm{O}_{2}$ não seja uma molécula reativa, ela pode dar origem a estados excitados reativos, como radicais livres e derivados. Radical livre é a molécula ou íon que contém um elétron sem-par, representado por uma letra com um ponto superior à direita (ex. $A^{\bullet}$ ), onde o ponto se refere ao elétron sem-par (Rice-Evans et al., 1991).

Segundo Scandalios (1993), a redução total do $\mathrm{O}_{2}$ a água, ocorre pela utilização de 4 elétrons numa via onde são gerados intermediários parcialmente reduzidos, como pode ser visto nas reações (1) e (2):

$$
\begin{aligned}
& \mathrm{O}_{2}+4 \mathrm{e}^{-}+4 \mathrm{H}^{+} \longrightarrow 2 \mathrm{H}_{2} \mathrm{O} \\
& \mathrm{O}_{2} \underset{\mathrm{H}^{+}}{\stackrel{+\mathrm{e}^{-}}{\longrightarrow}} \mathrm{O}_{2}^{--} \underset{\mathrm{H}^{+}}{\stackrel{+\mathrm{e}^{-}}{\longrightarrow}} \mathrm{H}_{2} \mathrm{O}_{2} \underset{\mathrm{H}^{+}}{\stackrel{+\mathrm{e}^{-}}{\longrightarrow}} \mathrm{OH}^{\bullet} \underset{\mathrm{H}^{+}}{\stackrel{+\mathrm{e}^{-}}{\longrightarrow}} \mathrm{H}_{2} \mathrm{O}
\end{aligned}
$$

A reação de dismutação de dois ânions superóxido $\left(\mathrm{O}_{2}^{-}\right)$, produz $\mathrm{H}_{2} \mathrm{O}_{2}$ (3). $\mathrm{O}$ mais altamente reativo e destrutivo radical livre de oxigênio, o radical oxidrilo $\left(\mathrm{OH}^{\circ}\right)$, é gerado pela transferência de um elétron do $\mathrm{O}_{2}{ }^{\circ-}$ para $\mathrm{H}_{2} \mathrm{O}_{2}(4)$ ou pela reação Fenton $(5$, 6). Nessa reação, radicais $\mathrm{O}_{2}^{-}$agem como agentes redutores de metais como $\mathrm{Fe}^{+3}$ e $\mathrm{Cu}^{+2}$, quando complexados com proteínas ou em quelatos de baixo peso molecular. Uma 
conseqüência importante da redução do metal é que esse, na presença de $\mathrm{H}_{2} \mathrm{O}_{2}$, pode conduzir à formação de $\mathrm{OH}^{\bullet}$.

$$
\begin{aligned}
& \mathrm{O}_{2}^{-}+\mathrm{O}_{2}^{-}+2 \mathrm{H}^{+} \longrightarrow \mathrm{H}_{2} \mathrm{O}_{2}+\mathrm{O}_{2} \\
& \mathrm{O}_{2}^{--}+\mathrm{H}_{2} \mathrm{O}_{2} \longrightarrow \mathrm{OH}^{-}+\mathrm{OH}^{\bullet}+\mathrm{O}_{2} \\
& \mathrm{O}_{2}^{-}+\mathrm{Fe}^{+3} \longrightarrow \mathrm{O}_{2}+\mathrm{Fe}^{+2} \\
& \mathrm{Fe}^{+2}+\mathrm{H}_{2} \mathrm{O}_{2} \longrightarrow \mathrm{Fe}^{+3}+\mathrm{OH}^{-}+\mathrm{OH}^{\bullet}
\end{aligned}
$$

Os radicais $\mathrm{O}_{2}^{-}$e $\mathrm{OH}^{\bullet}$, e o $\mathrm{H}_{2} \mathrm{O}_{2}$ são as EAOs biologicamente mais importantes. Todas elas são altamente reativas e citotóxicas em todos os organismos. As EAOs podem reagir com ácidos graxos insaturados das membranas e alterar sua funcionalidade. A alteração das membranas intracelulares, pode afetar a atividade respiratória em mitocôndrias, e diminuir a pigmentação e a capacidade de fixação de carbono em cloroplastos (Scandalios, 1993). O radical $\mathrm{OH}^{\bullet}$ pode reagir com todas as macromoléculas e causar sérios danos às células, como a peroxidação de lipídéos, inativação de enzimas e degradação de ácidos nucléicos (Mehdy, 1994).

Assim, a função do oxigênio é paradoxal. Por um lado, em sua forma molecular oxidada, é essencial para a vida aeróbia, por outro, em sua forma reduzida, é uma das substâncias mais tóxicas para os seres vivos.

\subsubsection{Transdução de sinais na explosão oxidativa}

Os mecanismos de sinalização e transdução de sinais envolvendo EAOs em interações planta-patógenos, não são totalmente compreendidos. Existem evidências sugerindo que as vias de sinalização em plantas são semelhantes às vias de sinalização em macrófagos de mamíferos e envolvem a chamada explosão oxidativa (Low \& Merida, 1996; Mehdy et al., 1996). 
Um modelo para explicar a indução de genes de defesa e a RH em interações planta-patógenos, através da geração de EAOs, foi proposto por Dangl et al. (1996). Nesse modelo, a percepção do elicitor, gerado pelo patógeno, por receptores na membrana plasmática vegetal, induz o influxo de $\mathrm{Ca}^{+2}$, a acidificação do citoplasma e a ativação de um complexo oxidase-NADPH, levando à produção de EAOs (Figura 1). As EAOs teriam efeito imediato no enrijecimento da parede celular, através da ação de peroxidases, além de serem reconhecidas pelas células vegetais, por um mecanismo desconhecido, resultando na ativação/desativação de fatores de transcrição de genes de defesa (Lamb \& Dixon,1997).

A participação de proteínas- $G$ na regulação da explosão oxidativa em plantas tem sido sugerida. $\mathrm{O}$ acúmulo de $\mathrm{H}_{2} \mathrm{O}_{2}$ em células de soja aumenta aproximadamente 10 vezes após a elicitação, quando fragmentos $F a b$ de anticorpos contra proteína-G conjugados à biotina são introduzidos nas células por endocitose (Legendré et al., 1992). Adicionalmente, um ativador de proteínas-G (mastoparana) estimula a liberação de EAOs na ausência de elicitor. Resultados semelhantes foram encontrados por Kauss \& Jeblick (1995) em salsa.

Foi demonstrado também que um incremento nos niveis de $\mathrm{Ca}^{+2}$ intracelular induz a produção de EAOs em algumas espécies de plantas. Em cultura de células de Picea abies e fumo, um bloqueador de canais de $\mathrm{Ca}^{+2}$, o lantânio $\left(\mathrm{La}^{+3}\right)$, inibiu a produção de EAOs após a elicitação (Schwacke \& Hager 1992; Baker et al., 1993). Adicionalmente, o tratamento de células de $P$. abies com ionóforo de $\mathrm{Ca}^{+2}$ (A23187) induziu a produção de EAOs (Schwacke \& Hager, 1992). Em cultura de células de salsa, Nürnberger et al. (1994) observaram que, após a elicitação, os níveis de $\mathrm{Ca}^{+2}$-intracelular aumentaram, coincidindo com a explosão oxidativa.

Inibidores de quinases e fosfatases de proteínas foram utilizados para estabelecer o papel da fosforilação na transdução de sinais em interações planta-microrganismos. A indução da explosão oxidativa em células de $P$. abies e fumo por bactérias ou elicitores foi bloqueada por pré-tratamento com os inibidores de quinases de proteínas, estaurosporina e K252-a, respectivamente (Schwacke \& Hager, 1992; Baker et al., 1993). Adicionalmente, inibidores de quinases de proteínas inibiram a produção de 


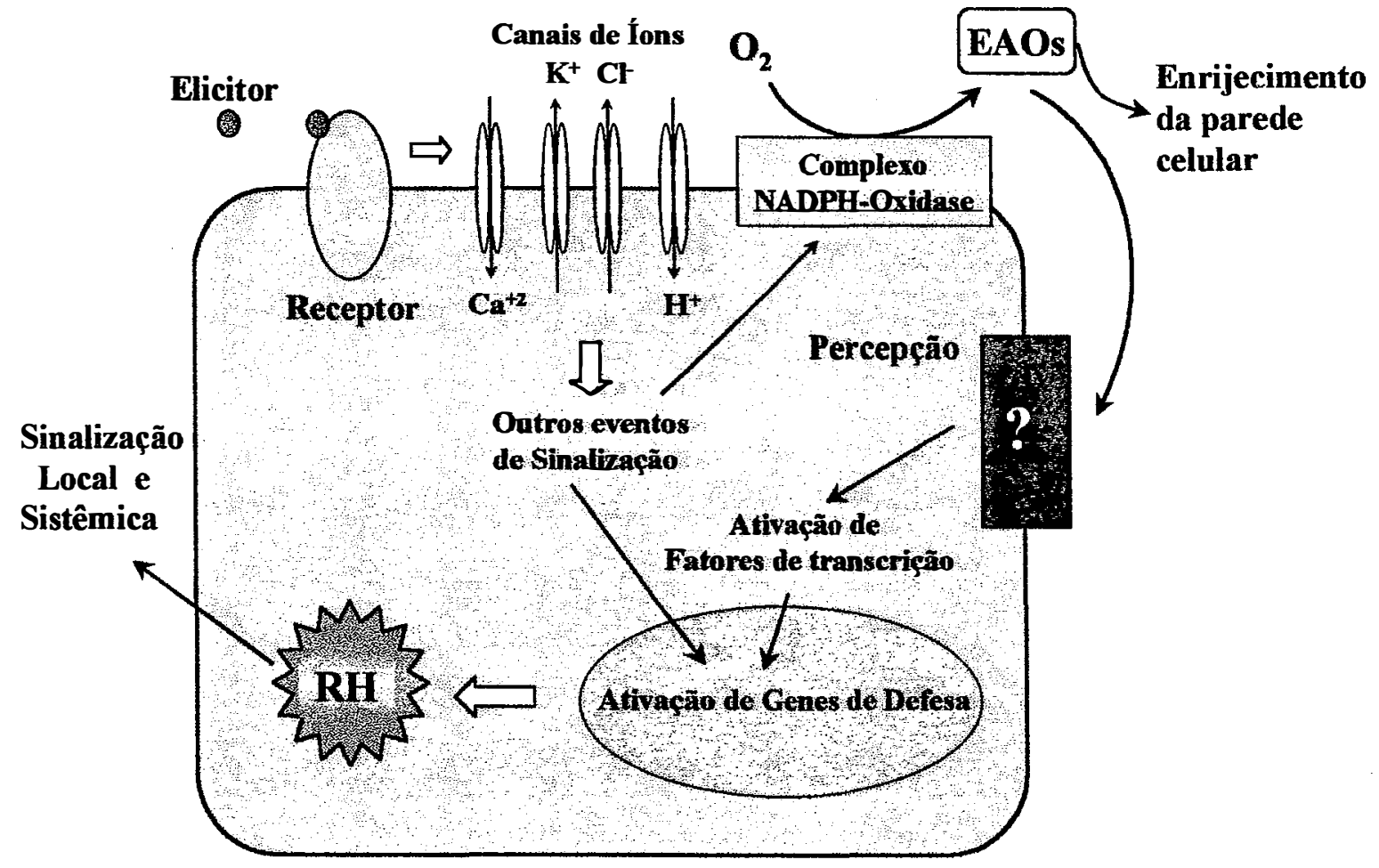

Figura 1. Modelo hipotético para a sinalização e transdução de sinais envolvendo espécies ativas de oxigênio (EAOs) em interações planta-patógenos. A ativação de genes de defesa resulta em reação de hipersensibilidade (RH) (Leite et al., 1997). 
$\mathrm{H}_{2} \mathrm{O}_{2}$, induzida por elicitor fúngico em células de soja (Levine et al., 1994, Chandra \& Low, 1995) e em células de salsa (Kauss \& Jeblick, 1995).

Algumas evidências sugerem que o complexo NADPH-oxidase, presente em macrófagos de mamíferos, também tem papel fundamental na geração de EAOs em plantas. Geração de $\mathrm{O}_{2}^{-}$, dependente da atividade de $\mathrm{NADPH}$, em células de batata infectadas por uma raça incompatível de Phytophthora infestans foi observado (Doke, 1983). Recentemente foi demonstrado que frações da membrana plasmática de células de batata infectadas com uma raça incompativel de Phytophthora infestans contém níveis de atividade de oxidase superiores às frações correspondentes de células infectadas com uma raça compatível (Doke \& Miura, 1995).

\subsubsection{Funções da explosão oxidativa}

Estudos recentes indicam que $\mathrm{H}_{2} \mathrm{O}_{2}$ produzido durante a explosão oxidativa tem papel fundamental na $\mathrm{RH}$, participando de processos bioquímicos relacionados ao enrijecimento da parede celular vegetal, à morte programada (apoptose) das células vegetais elicitadas e à indução sistêmica de genes de defesa em células não-infectadas (Tenhaken et al., 1995; Dangl et al., 1996). O tratamento de células de feijão em suspensão com $\mathrm{H}_{2} \mathrm{O}_{2}$ induz o acúmulo de mRNAs codificando enzimas envolvidas na biossíntese de fitoalexinas e endoquitinases, de maneira similar a elicitores derivados da parede celular fúngica, sugerindo sua participação na transdução de sinais em interações planta-patógenos (Mehdy, 1994). Outra evidência da participação de $\mathrm{H}_{2} \mathrm{O}_{2}$ como mensageiro secundário na transdução de sinais é a ausência de acúmulo de mRNAs de genes de defesa após elicitação de células em suspensão na presença de inibidores da geração de $\mathrm{H}_{2} \mathrm{O}_{2}$ (Sharma, 1992; Mehdy, 1994). As EAOs podem regular também a estabilidade de mRNAs relacionados à defesa vegetal e de fatores de transcrição (Mehdy, 1994).

A indução de genes de defesa em locais distantes do sítio de infecção implica na existência de moléculas sinalizadoras que se movimentam através da planta. Foi proposto que esse sinal de longa distância seria o $\mathrm{H}_{2} \mathrm{O}_{2}$ (Ryals et al., 1996). Uma 
proteína que se liga ao ácido salićlico (AS) isolada de fumo foi identificada como sendo uma catalase, cuja atividade enzimática é inibida por AS. Assim, acúmulo de AS resultaria em aumento de concentração de $\mathrm{H}_{2} \mathrm{O}_{2}$ (Chen et al., 1993). Verificou-se, no entanto, que não há acúmulo de $\mathrm{H}_{2} \mathrm{O}_{2}$ em tecidos desenvolvendo resposta sistêmica adquirida (RSA) e $\mathrm{H}_{2} \mathrm{O}_{2}$ não induz $\mathrm{RSA}$ em plantas transgênicas que não acumulam $\mathrm{AS}$ (Neuenschwander et al., 1995; Yong-Mei et al., 1995). Adicionalmente, a indução de uma proteína-RP em fumo por $\mathrm{H}_{2} \mathrm{O}_{2}$ só ocorre na presença de AS, indicando que $\mathrm{H}_{2} \mathrm{O}_{2}$ não é um mensageiro secundário durante a indução de RSA por AS (Neuenschwander et al., 1995). Dessa forma, o efeito inibitório de AS sobre a atividade de catalase pode ser importante somente para contenção do patógeno na região do sítio de infecção.

\subsubsection{Mecanismos de remoção das espécies ativas de oxigênio}

Vários mecanismos para a remoção de EAOs produzidas durante o metabolismo celular e em resposta a estresses já foram identificados. Dentre eles, a indução de enzimas capazes de neutralizar EAOs e/ou seus intermediários é o mais comum. Entre as enzimas anti-EAOs encontram-se as superóxido dismutases (SODs), catalases (CATs) e peroxidases (POXs). As SODs e CATs, conjuntamente, convertem $\mathrm{O}_{2}{ }^{-}$e $\mathrm{H}_{2} \mathrm{O}_{2}$ em água e oxigênio molecular. A ação dessas enzimas antioxidantes pode evitar a formação de EAOs mais reativas. A defesa não enzimática inclui os compostos sulfidrílicos nãoprotéicos de baixa massa molecular como glutationa, cisteína e cisteinilglicina, assim como hidroquinonas, alopurinol, mucina, manitol, dimetilsulfóxido (DMSO), vitaminas C e E, uratos, ferridoxina e $\beta$-carotenos (Sies, 1993). Nesta revisão serão abordados apenas aspectos relacionados às SODs, CATs e POXs.

\subsection{Superóxido dismutases}

As SODs (EC 1.15.1.1) geralmente ocorrem em três diferentes formas moleculares, dependendo do íon metálico associado. Assim, existem SODs contendo cobre e zinco ( $\mathrm{Cu} / \mathrm{Zn}$-SOD), manganês (Mn-SOD) ou ferro (Fe-SOD). Essas isoenzimas 
encontram-se amplamente distribuídas nos organismos aeróbios, anaeróbios facultativos e alguns anaeróbios obrigatórios (Scandalios, 1990). Cu/Zn-SODs, estão presentes geralmente no citoplasma de células eucarióticas e cloroplastos; Mn-SODs, na matriz de mitocôndrias e em procariotos; Fe-SODs, são geralmente encontrados em procariotos (Fridovich, 1986; Scandalios, 1993). A massa molecular dessas isoformas, dependendo da estrutura dimérica ou tetamérica que apresentam, varia entre 30 a $90 \mathrm{kDa}$ (Scandalios, 1990).

Esse grupo de enzimas catalisa a dismutação de radicais livres de $\mathrm{O}_{2}{ }^{\circ-}$ a $\mathrm{H}_{2} \mathrm{O}_{2}$ e $\mathrm{O}_{2}$, segundo a reação:

$$
2 \mathrm{O}_{2}{ }^{--}+2 \mathrm{H}^{+} \stackrel{\text { SOD }}{\longrightarrow} \mathrm{H}_{2} \mathrm{O}_{2}+\mathrm{O}_{2}
$$

Nos últimos anos, diferentes estudos foram realizados com o objetivo de entender o papel das SODs no metabolismo de EAOs em vegetais, sob as mais variadas condições, tais como: alta concentração de oxigênio (Foster \& Hess, 1980), estresse por metais (Cakmak \& Horst, 1991; Weckx \& Clijsters, 1996), poluentes do ar e xenobióticos (Palma et al., 1991; Rao et al., 1996), estresse hídrico (Gogorcena et al., 1995) e estresse por baixas temperaturas (Pinheiro et al., 1997). Em todos estes casos foi observada a participação direta das EAOs nos danos celulares e a indução de SODs como um importante mecanismo de proteção das plantas.

Em interações planta-patógenos, Ádám et al. (1995) observaram um incremento das atividades de SOD na interação incompativel Phaseolus vulgaris-Pseudomonas syringae raça 1). No entanto, na interação compativel, com a raça 3, não observaram mudanças nas atividades de SOD durante a infecção, sugerindo sua direta participação na RH. Em contraste, Milosevic \& Slusarenko (1996), no mesmo sistema biológico, não observaram incrementos nas atividades de SOD em nenhuma das interações (incompatíveis ou compatíveis), sugerindo que a produção de $\mathrm{H}_{2} \mathrm{O}_{2}$, via dismutação de radicais $\mathrm{O}_{2}{ }^{\bullet-}$ pela SOD, não seria a principal fonte dessa EAO. 
Vanacker et al. (1998) estudaram o padrão de atividade de SOD em folhas de cevada (Hordeum vulgare) infectadas pelo fungo Blumeria graminis Alg-R (interação incompatível) e verificaram um incremento de $150 \%$ em relação aos controles nãoinfectados. $\mathrm{Na}$ interação com B. graminis Alg-S (interação compatível), as atividades de SODs foram $300 \%$ maiores do que nos controles não-infectados, o que sugere um incremento na produção de $\mathrm{H}_{2} \mathrm{O}_{2}$.

Estudos das SODs foram realizados em associações mutualísticas, em interações leguminosas-Rhizobium (Gogorcena et al., 1995) e Alnus incana-Frankia (Puppo et al., 1989; Alskog \& Huss-Danell, 1997), relacionando a importância dessas enzimas nos processos de proteção antioxidativa da nitrogenase durante a fixação biológica do nitrogênio.

O papel das SODs durante o desenvolvimento de MAs ainda é desconhecido. Somente quatro estudos relacionados à atividade de SODs em MAs foram reportados. Palma et al. (1993) observaram, em simbioses de Trifolium pratense com Glomus mosseae, que certas isoenzimas de SOD são induzidas pelo fungo micorrízico, provavelmente, como conseqüência de um incremento na geração de $\mathrm{O}_{2}{ }^{-*}$ nas raízes. Arines et al. (1994), estudando o sistema simbiótico Pisum sativum-G. mosseae, avaliaram os padrões eletroforéticos e as atividades de SODs em raízes micorrizadas e não-micorrizadas. Os resultados mostraram que certas isoformas de SOD eram expressas preferencialmente em raízes micorrizadas.

Ruiz-Lozano et al. (1996) estudaram as atividades de SOD em MAs sujeitas a estresse hídrico (potencial de água no solo de -0,17 MPa). Nessas condições, plantas de alface (Lactuca sativa) colonizadas por G. mosseae ou Glomus deserticola apresentaram maior atividade específica de SOD em relação aos controle não-inoculados. Em condições não estressantes $(-0,04 \mathrm{MPa})$, as diferenças não foram significativas. Os autores concluíram que a indução de SODs em plantas micorrizadas estaria diretamente relacionada aos mecanismos de interação entre o FMA e a planta, em resposta aos períodos de seca.

Indução das atividades de SOD em diferentes períodos do desenvolvimento de MAs foram observados por Martin et al. (1998) em associações de T. pratense com $G$. 
mosseae ou $G$. intraradices. Os resultados obtidos foram atribuídos a possiveis alterações do estado fisiológico das raízes durante o envelhecimento da planta, período no qual existe um incremento na concentração de EAOs.

\subsection{Catalases}

As CATs (EC 1.11.1.6) são enzimas amplamente distribuídas na natureza, e estão presentes em todas as células de plantas, animais e microrganismos aeróbios. Localizamse no citoplasma e nas organelas (mitocôndrias, peroxissomos e cloroplastos), atuando como reguladoras dos níveis de $\mathrm{H}_{2} \mathrm{O}_{2}$. CATs são hemeproteínas tetraméricas, constituídas de 4 subunidades de $60 \mathrm{kDa}$ cada. Contém 4 grupos ferriprotoporfirinas por molécula, com massa molecular aproximada de $240 \mathrm{kDa}$ (Scandalios, 1990).

A atividade das catalases consiste na decomposição de $\mathrm{H}_{2} \mathrm{O}_{2}$, originando $\mathrm{H}_{2} \mathrm{O}$ e $\mathrm{O}_{2}$, segundo a reação:

$$
2 \mathrm{H}_{2} \mathrm{O}_{2} \stackrel{\mathrm{CAT}}{\longrightarrow} 2 \mathrm{H}_{2} \mathrm{O}+\mathrm{O}_{2}
$$

Em interações planta-patógenos, Ádám et al. (1995) e Milosevic \& Slusarenko (1996) não observaram alterações significativas nas atividades de CAT em interações compatíveis no sistema Phaseolus vulgaris-Pseudomonas syringae. No entanto, em interações incompatíveis, observaram supressão das atividades de CAT durante o processo de infeç̧ão, sugerindo que o acúmulo de $\mathrm{H}_{2} \mathrm{O}_{2}$ induziria a ativação do sistema de defesa vegetal.

Vanacker et al. (1998) estudando a associação entre cevada e o fungo $B$. graminis, observaram um incremento de $400 \%$ da atividade de CAT em associações compatíveis, em relação ao controle não-infectado. Em associações incompativeis, não observaram alterações significativas nas atividades de CATs.

Recentemente, CATs foram implicadas na transdução de sinais durante o desenvolvimento da RSA em plantas, sugerindo que muitos compostos que induzem a expressão de genes relacionados à patogênese e resistência, direta ou indiretamente, 
interagem com catalases. Foi proposto um modelo no qual o AS liga-se a uma CAT, inativando-a e contribuindo para o aumento do nível de $\mathrm{H}_{2} \mathrm{O}_{2}$ e desenvolvimento de RSA nos tecidos não infectados (Ryals et al., 1996). Outro modelo propõe a geração de $\mathrm{O}_{2}$ pela dismutação de $\mathrm{H}_{2} \mathrm{O}_{2}$ produzido durante a explosão oxidativa em resposta ao patógeno (Leon et al., 1995). A resistência a doenças pode ser conferida por elevados niveis de $\mathrm{H}_{2} \mathrm{O}_{2}$ e esta resistência é neutralizada por atividades de CATs (Wu et al., 1995). Embora as funções de CATs não sejam bem conhecidas em interações plantamicrorganismos, é provável que elas tenham importante papel na transdução de sinais e ativação do sistema de defesa.

O número de isoenzimas de CAT em vegetais é variável. Em folhas de feijão ( $P$. vulgaris) foi observado somente uma isoforma $\left(\right.$ Braber $^{1}, 1980$, citado por Havir \& Mchale, 1987). A mamona (Ricinus communis) apresenta duas isoformas, em cotilédones e somente uma em raizes (Ota et al., 1992). Folhas de fumo apresentam três isoformas (Havir e Mchale, 1987), embriões de milho, cinco (Williamson \& Scandalios, 1993), Arabidopsis thaliana, seis (duas em raízes) (Frugoli et al., 1996) e cotilédones de mostarda (Sinapsis alba) 12 isoformas (Drumm \& Schofer, 1974).

\subsection{Peroxidases}

As POX (EC 1.11.1.7) ocorrem em células vegetais, certas células animais e microrganismos (Hoagland, 1990). São hemeproteínas, com massa molecular em torno de $40 \mathrm{kDa}$ (Bergmeyer et al., 1963; Van Huystee, 1987), que desempenham várias funções, entre elas: catalizam a oxidação e a eventual polimerização de álcool hidroxicinâmico em presença de peróxido de hidrogênio, originando lignina (Intapruk et al., 1994); participam da biossintese do hormônio vegetal etileno (Ishige et al., 1993); participam da oxidação de compostos fenólicos (Fry, 1986); participam da oxidação do ácido indol-3-acético (Hoagland, 1990).

${ }^{1}$ BRABER, J.M. Catalase and peroxidase in primary bean leaves during development and senescence. Z. Pflanzenphysiol, v.97, p.135-144, 1980. 
A reação das POXs consiste de dois passos sucessivos, envolvendo um elétron cada. Uma equação geral para reações catalisadas por POX não pode ser formulada, já que o curso da reação depende do tipo de substrato (fenóis, aminofenóis, diaminas, indofenóis, ascorbatos e muitos aminoácidos) (Bergmeyer et al., 1974). No caso, onde a mesma molécula orgânica é doadora de elétrons para ambos os passos, a equação seria:

$$
\mathrm{H}_{2} \mathrm{O}_{2}+\mathrm{AH}_{2} \stackrel{\mathrm{POX}}{\longrightarrow} 2 \mathrm{H}_{2} \mathrm{O}+\mathrm{A}
$$

Mudanças nas atividades de peroxidases têm sido freqüentemente correlacionadas à resposta de resistência ou suscetibilidade em diferentes patossistemas. Essa relação já foi demonstrada em feijão-Uromyces viceae-fabae (Bonatti et al., 1994), feijão-P. syringae (Ádám et al., 1995; Milosevic \& Slusarenko, 1996), feijão-vírus do mosqueado (PMV) (Wagih, 1993), por exemplo.

Entre os trabalhos relacionados com as atividades de POXs durante $o$ desenvolvimento de MAs, poder-se-ia citar os estudos realizados em raízes de Allium porrum, os quais revelaram um incremento de atividade enzimática nas etapas iniciais da colonização das raizes por G. versiforme e posterior supressão (Spanu \& BonfanteFasolo, 1988). Resultados semelhantes foram observados por Fries et al. (1996) na interação Zea mays-G. intraradices. McArthur \& Knowles (1992, 1993), estudando o padrão de atividade de POXs em raizes de batata em condições de baixo e alto $\mathrm{P}$ no solo, observaram baixo nível de atividades em raízes sob baixo $\mathrm{P}$ e indução em condições de alto P. Mathur \& Vyas (1995) na interação Ziziphus-G. fasciculatum, também observaram aumentos das atividades de POXs em resposta ao incremento de $\mathrm{P}$ disponível para as plantas e à indução de isoformas vegetais específicas pelo FMA. 


\section{MATERIAL E METODOS}

\subsection{Instalação do experimento}

O experimento foi instalado e conduzido em casa-de-vegetação nas dependências do Departamento de Ciência do Solo, da Escola Superior de Agricultura "Luiz de Queiroz", Piracicaba, Estado de São Paulo, sob condições controladas de temperatura e umidade.

O delineamento experimental utilizado foi inteiramente casualizado, em esquema fatorial $3 \times 2 \times 4$ com 4 repetições, sendo 3 os níveis do fator "fungos micorrízicos" (controle, G. intraradices e G. clarum ), 2 os níveis do fator "doses de P" (20 e $150 \mathrm{mg}$ de $\mathrm{P} \mathrm{kg}^{-1}$, na forma de $\left.\mathrm{KH}_{2} \mathrm{PO}_{4}\right)$ e 4 os níveis do fator "épocas de amostragem" $(4,6,8 \mathrm{e}$ 10 semanas após inoculação), perfazendo um total de 96 unidades experimentais. A unidade experimental foi constituída por vasos com $1,5 \mathrm{~kg}$ de substrato, contendo uma planta de feijão ( $P$. vulgaris $\mathrm{L}$. var. Carioca $80-\mathrm{SH})$.

As sementes de feijão, cedidas pelo Instituto Agronômico de Campinas (IAC), foram desinfestadas em solução de hipoclorito de sódio comercial com uma concentração aproximada de $2 \%$, durante 4 min e lavadas em água destilada esterilizada durante $15 \mathrm{~min}$, com trocas a cada $5 \mathrm{~min}$ até o momento da colocação em placas-de-petri esterilizadas, com algodão umedecido para germinarem. As sementes foram incubadas a $28^{\circ} \mathrm{C}$ no escuro por aproximadamente $48 \mathrm{~h}$. Após a germinação, sementes com radículas foram plantadas em vasos contendo $1,5 \mathrm{~kg}$ de uma mistura de areia de rio (peneirada em peneira de malha de $2 \mathrm{~mm}$ ) e vermiculita na proporção $3: 1(\mathrm{v} / \mathrm{v})$, previamente lavadas e esterilizadas em autoclave a $121^{\circ} \mathrm{C}$ por $2 \mathrm{~h}$. 
Foram feitas aplicações de nutrientes em solução, dois dias antes da inoculação. Assim, plantas não-inoculadas e inoculadas com FMAs, cultivadas sob baixo P (20 mg de $P \mathrm{~kg}^{-1}$ de substrato) e sob alto $\mathrm{P}$ ( $150 \mathrm{mg}$ de $\mathrm{P} \mathrm{kg}{ }^{-1}$ de substrato) receberam $80 \mathrm{mg} \mathrm{N}$ (aplicado parcelado em 3 vezes, a cada 15 dias), $150 \mathrm{mg} \mathrm{K}, 50 \mathrm{mg} \mathrm{Ca}, 35 \mathrm{mg} \mathrm{Mg}, 2 \mathrm{mg}$ Fe e $0,2 \mathrm{~mL}$ de solução de micronutrientes de Hoagland por kg de substrato. A umidade do substrato foi mantida em aproximadamente $70 \%$ da capacidade máxima de retenção de água, através de regas diárias com água destilada esterilizada. A temperatura durante o período de cultivo na casa-de-vegetação foi mantida a $26 \pm 4^{\circ} \mathrm{C}$. Externamente, a radiação média foi de $371,38 \mathrm{cal} / \mathrm{cm}^{2} / \mathrm{dia}$, enquanto que a insolação média foi de 6,96 h/dia. A Figura 2, mostra as plantas de feijoeiro na casa-de-vegetação, aos 55 dias após transplantio.

A inoculação com os fungos micorrízicos G. intraradices ou $G$. clarum foi realizada no momento do transplantio. Como fonte de inóculo, usou-se uma suspensão com 200 esporos $\mathrm{mL}^{-1}$, para cada fungo (total de 2000 esporos vaso ${ }^{-1}$ ), aplicada sob as sementes pré-germinadas. Os esporos foram isolados por lavagem e peneiramento úmido de solo provenientes de vasos de multiplicação com Brachiaria decumbens, conforme descrito por Gerdemann \& Nicolson (1963). O tratamento controle (não-inoculado) recebeu o mesmo volume de suspensão; porém, proveniente de vasos de multiplicação com Brachiaria, não-inoculada, visando manter a mesma microbiota bacteriana dos tratamentos que receberam fungos micorrízicos.

\subsection{Análises laboratoriais}

\subsubsection{Obtenção das raízes de feijão e avaliação do nível de colonização}

Em cada época de colheita do experimento, a parte aérea das plantas foi separada das raízes, seca em estufa com circulação forçada de ar a $65^{\circ} \mathrm{C}$, até massa constante, para a determinação da massa da matéria seca da parte aérea (MSPA). As raízes foram rapidamente lavadas em água corrente, secas em papel absorvente e após a determinação da massa do material fresco e retirada de cerca de $1,0 \mathrm{~g}$ do terço médio da raiz de cada 


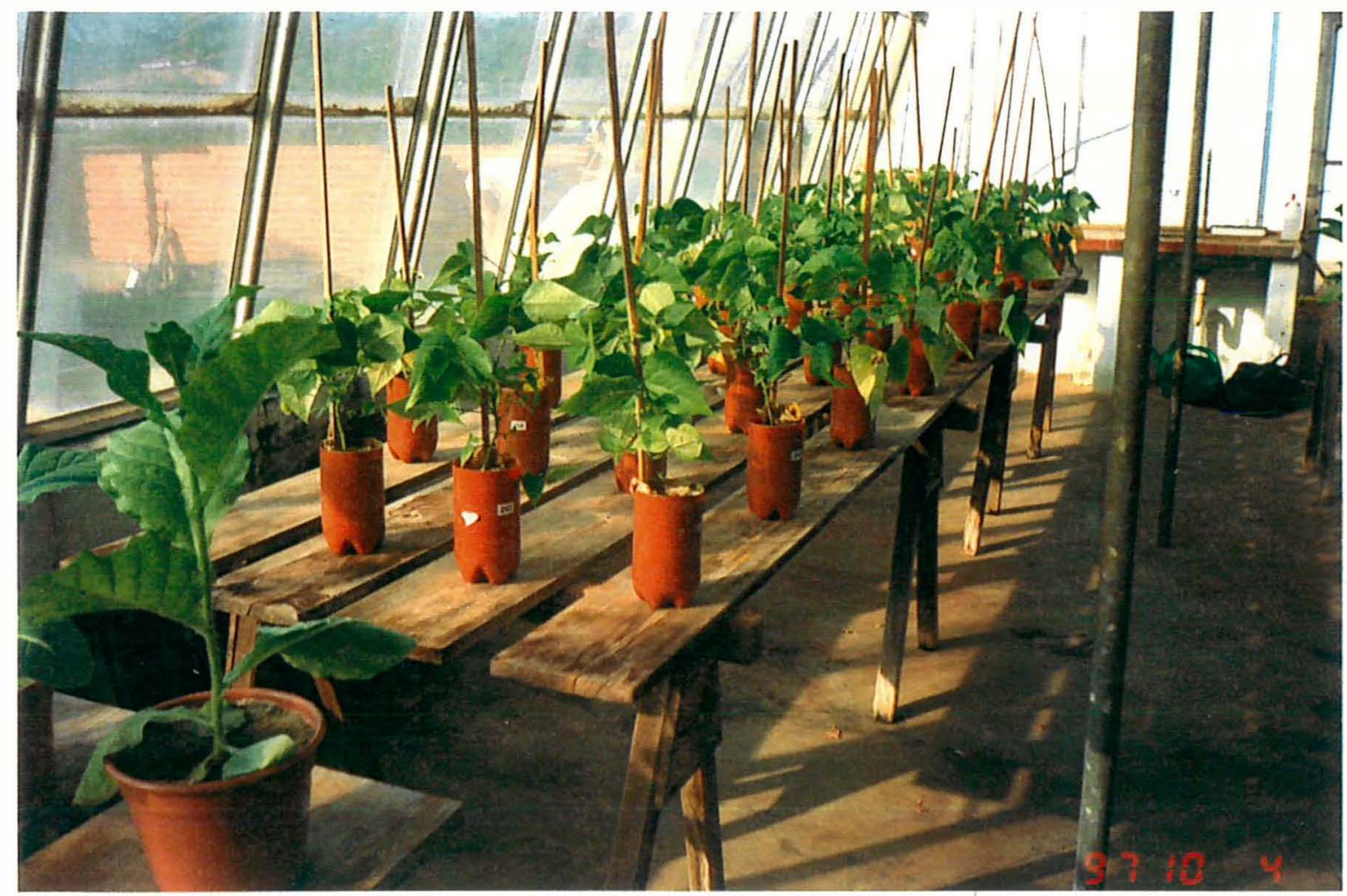

Figura 2. Vista geral das plantas de feijoeiro na casa-de-vegetação, aos 55 dias após transplantio. 
planta para determinação do nível de colonização, as mesmas foram armazenadas a $-80^{\circ} \mathrm{C}$ para as análises bioquímicas.

A determinação do nível de colonização das raízes pelos FMAs foi feita pelo método descrito por Phillips \& Hayman (1970). As raízes foram descoloridas com solução de $\mathrm{KOH}(10 \%)$ em banho maria a $90^{\circ} \mathrm{C}$ por $45 \mathrm{~min}$, lavadas com água corrente, e acidificadas em solução de $\mathrm{HCl}(10 \%)$ por $3 \mathrm{~min}$. Em seguida, as raízes foram coloridas com solução de azul-de-tripano $0,05 \%$ em lactoglicerol por 5 min a $90^{\circ} \mathrm{C}$. A avaliação foi feita por microscopia, determinando-se a presença de estruturas fúngicas (hifas, arbúsculos, vesículas) no tecido cortical (Figura 3), em placas reticuladas, segundo o método descrito por Giovannetti \& Mosse (1980).

\subsubsection{Extração de proteínas}

Aproximadamente $3 \mathrm{~g}$ de raízes não-colonizadas ou colonizadas com G. clarum ou G. intraradices, foram maceradas em nitrogênio líquido e homogeneizadas em $9 \mathrm{~mL}$ de solução de extração contendo tampão fosfato $100 \mathrm{mM}, \mathrm{pH}$ 7,5; EDTA (etilenodiaminotetracético) 1mM; PMSF (parametilsulfonilfluoreto) $1 \mathrm{mM}$ e PVPP (polivinilpolipirrolidona) $0,5 \%(\mathrm{~m} / \mathrm{v})$. Após a obtenção do sobrenadante, através de duas centrifugações sucessivas $\left(5.000 \mathrm{~g}, 5 \mathrm{~min}, 4^{\circ} \mathrm{C}\right.$ e $\left.20.000 \mathrm{~g}, 20 \mathrm{~min}, 4^{\circ} \mathrm{C}\right)$, utilizou-se todo o sobrenadante (c.a. $9 \mathrm{~mL}$ ) para precipitação das proteínas com sulfato de amônio (90\% de saturação a $0^{\circ} \mathrm{C}$ ), por $2 \mathrm{~h} \mathrm{a} 4^{\circ} \mathrm{C}$, sob agitação. Após centrifugação a $10.000 \mathrm{~g}$ por 10 $\min , 4^{\circ} \mathrm{C}$, o precipitado obtido foi dissolvido em $1,5 \mathrm{~mL}$ de tampão fosfato $100 \mathrm{mM} \mathrm{pH}$ 7,5. Essa solução foi submetida a filtração em gel de Sephadex G-25 a $4^{\circ} \mathrm{C}$. Após obtenção do eluente ( $3 \mathrm{~mL})$, adicionou-se glicerol até concentração de 12,5\% (v/v). Este extrato foi dividido em frações de $500 \mu \mathrm{L}$ e armazenado a $-80^{\circ} \mathrm{C}$ para posterior determinação da concentração de proteínas e análises das atividades de SOD, CAT e POX. 

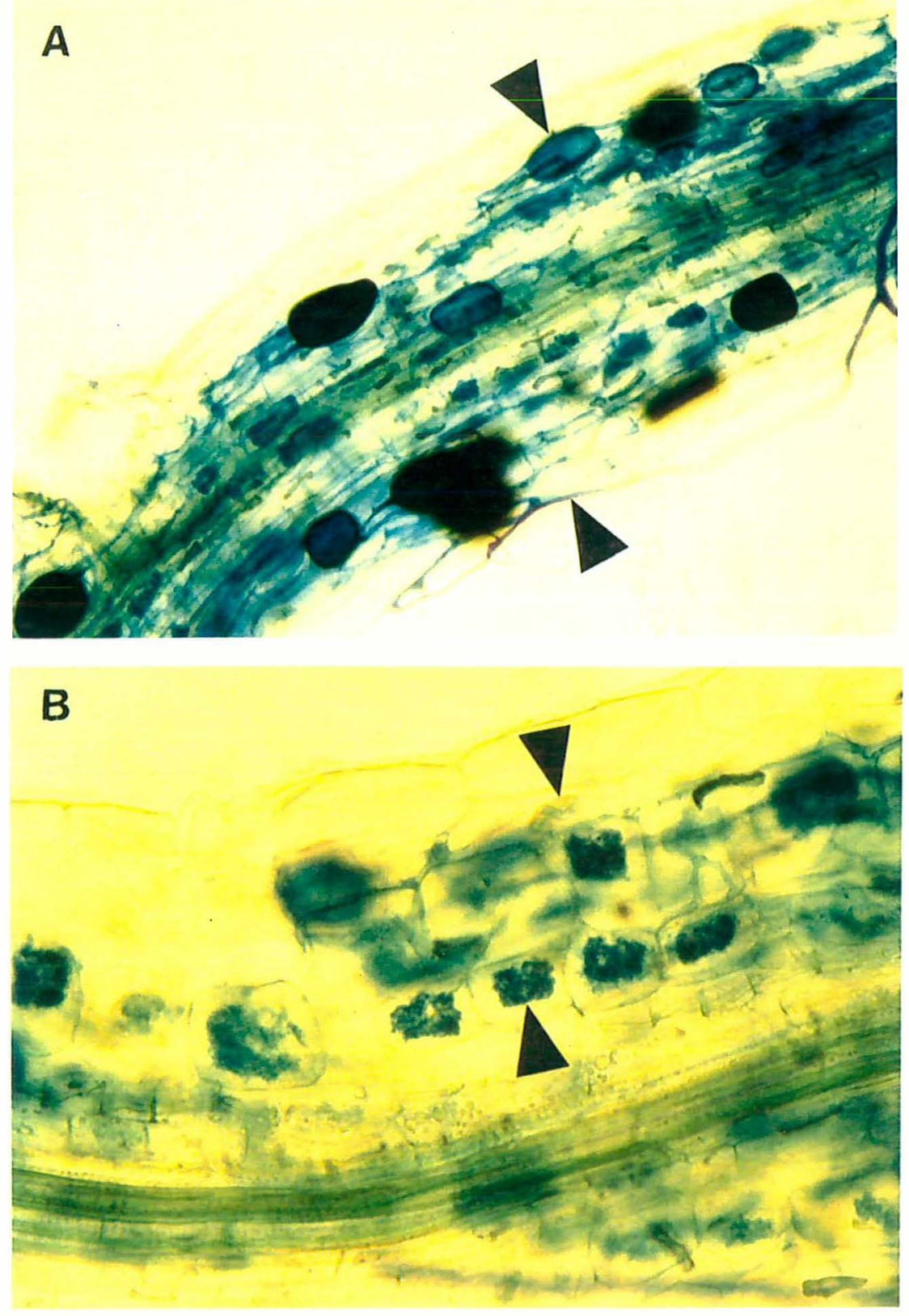

Figura 3. Aspectos morfológicos de micorrizas arbusculares em raizes de feijoeiro colonizadas por G. clarum. A: seta superior, vesícula; seta inferior, hifa. B: seta superior, hifa; seta inferior, arbúsculo. 


\subsubsection{Determinação do conteúdo total de proteínas}

A concentração de proteínas foi determinada segundo o método de Bradford (1976), em microplacas. Para tanto, foram adicionados a cada $25 \mu \mathrm{L}$ do extrato de cada

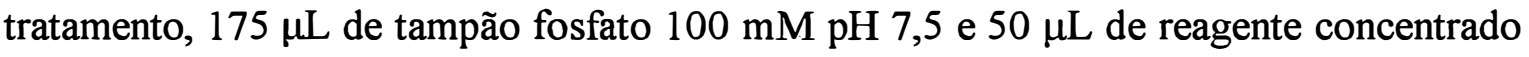
do kit para determinação de proteínas da Bio-Rad. Após a mistura das soluções nos "poços" da placa, foram determinadas as absorbâncias a $595 \mathrm{~nm}$. A concentração de proteínas no extrato de cada tratamento foi determinada utilizando-se curva padrão com albumina de soro bovino (ASB) ( 8 a $40 \mu \mathrm{g} \mathrm{mL}^{-1}$ ). A concentração de proteínas foi expressa em equivalentes $\mu \mathrm{g}$ de ASB por $\mathrm{mL}$ de extrato $\left(\mu \mathrm{g}\right.$ proteína $\left.\mathrm{mL}^{-1}\right)$.

\subsubsection{Determinação das atividades de superóxido dismutase}

A determinação das atividades de SOD apresenta uma certa dificuldade, já que seu substrato, o radical $\mathrm{O}_{2}{ }^{*}$ deve ser gerado no processo de análise, mas não pode ser medido diretamente. A medida indireta consiste em usar um indicador da concentração de $\mathrm{O}_{2}^{*}$, o qual serve como índice da atividade de SOD no sistema. O sistema xantina/xantina oxidase é usado para gerar $\mathrm{O}_{2}{ }^{*-}$ e a taxa de redução de citocromo $c$ por $\mathrm{O}_{2}{ }^{*-}$ é monitorado a $550 \mathrm{~nm}$. A inibição desta redução quando é adicionado o preparado contendo SOD serve como uma medida de sua atividade. A SOD provoca a dismutação do $\mathrm{O}_{2}{ }^{\circ-}$, substrato necessário para redução de citocromo $c$, segundo as reações (Flohé \& Öting, 1984):

$$
\begin{gathered}
\text { Xantina }+\mathrm{O}_{2} \stackrel{\text { Xantina Oxidase }}{\longrightarrow} \mathrm{O}_{2}^{*-}+\text { ácido úrico } \\
\mathrm{O}_{2}^{*-}+\text { citocromo } c\left(\mathrm{Fe}^{3+}\right) \longrightarrow \mathrm{O}_{2}+\text { citocromo } c\left(\mathrm{Fe}^{2+}\right) \\
2 \mathrm{O}_{2}^{*-}+2 \mathrm{H}^{+} \stackrel{\mathrm{SOD}}{\longrightarrow} \mathrm{H}_{2} \mathrm{O}_{2}+\mathrm{O}_{2}
\end{gathered}
$$


As atividades de SOD foram avaliadas segundo Flohé \& Öting (1984), em $1 \mathrm{~mL}$

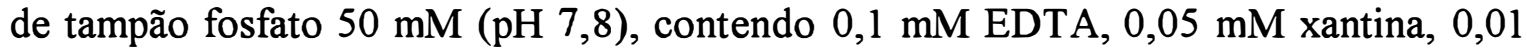
$\mathrm{mM}$ citocromo $c, 10-40 \mu \mathrm{L}$ de extrato de proteínas e xantina oxidase $\left(\sim 0,2 \mathrm{U} \mathrm{mL}^{-1}\right)$. Após a mistura, foi determinada a variação da absorbância a $550 \mathrm{~nm}$ por 1 min. Para a reação controle, utilizou-se água desionizada no lugar do extrato de proteínas, determinando-se uma redução de 0,030 unidades de absorbância a $550 \mathrm{~nm}$ por min. A atividade de SOD foi expressa em Unidades $\mathrm{mg}^{-1}$ proteínas. Uma unidade da atividade de SOD é definida como a quantidade de enzima que inibe á redução de citocromo $c$ em $50 \%$.

Para a obtenção de uma unidade de SOD, primeiro determinou-se a variação da absorbância $\min ^{-1}$ no controle, variando as quantidades de xantina oxidase até a obtenção de uma diferença de 0,030 unidades de absorbância. Baseado no controle, 50\% de inibição seria a diferença de 0,015 unidades de absorbância $\min ^{-1}$. Em seguida, foram determinadas as variações de absorbâncias com a adição de 10,20 e $40 \mu \mathrm{L}$ dos extratos. A inibição de $50 \%$ da redução de citocromo $c$ foi determinada através de análise de regressão.

\subsubsection{Determinação das atividades de catalases}

As atividades de CATs foram avaliadas segundo Aebi (1984), em tampão fosfato

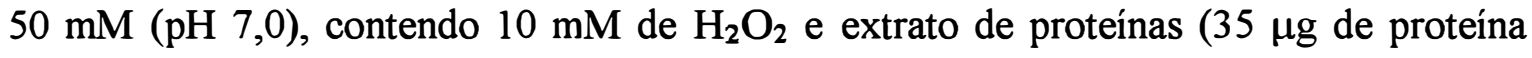
total), em um volume final de $1 \mathrm{~mL}$. A decomposição do $\mathrm{H}_{2} \mathrm{O}_{2}$ foi avaliada por decréscimo na absorbância a $240 \mathrm{~nm}$, durante $2 \mathrm{~min}$. O branco consistiu de solução contendo extrato de proteínas ( $35 \mu \mathrm{g}$ de proteína total) e tampão fosfato até $1 \mathrm{~mL}$. As atividades de CATs foram expressas como $-\Delta \mathrm{A}_{240} \mathrm{mg}^{-1}$ proteína $\mathrm{min}^{-1}$.

\subsubsection{Caracterização isoenzimática de catalases em géis de poliacrilamida}

A eletroforese anódica em gel de poliacrilamida descontínuo não-desnaturante foi conduzida utilizando-se o equipamento de eletroforese vertical Mini Protean II (Bio- 
Rad). A concentração do gel concentrador foi de $4 \%$ e do gel de corrida de $10 \%$. Como tampão de corrida utilizou-se Tris-glicina $(\mathrm{pH} 8,3)$. A eletroforese foi realizada com duas unidades de catalase de figado de boi (Boehringer Mannheim), como controle positivo e $30 \mu \mathrm{g}$ de proteína total dos diferentes tratamentos, a $4^{\circ} \mathrm{C}$ e corrente constante de $20 \mathrm{~mA}$ por gel. A corrida foi interrompida quando o corante da amostra atingiu a porção final do gel.

Woodbury et al. (1971) descreve um método de coloração de géis de poliacrilamida para a caracterização isoenzimática de CATs onde utiliza $\mathrm{H}_{2} \mathrm{O}_{2}$ para reduzir ferrocianeto de potássio $\mathrm{II}$ a ferrocianeto de potássio II, sendo o $\mathrm{H}_{2} \mathrm{O}_{2}$ oxidado para oxigênio molecular. $\mathrm{O}$ cloreto de ferro reage com o ferrocianeto II resultando em um pigmento verde escuro, cor que apresenta o gel, em contraste com as bandas de CAT que aparecem amarelas.

A detecção de proteínas com atividade de CAT foi feita segundo a metodologia de Woodbury et al. (1971). O gel foi lavado com água desionizada por $45 \mathrm{~min}$ (com troca a cada $15 \mathrm{~min}$ ) sob agitação e imerso em $\mathrm{H}_{2} \mathrm{O}_{2}$ 0,003\% (v/v) por $10 \mathrm{~min}$. Em seguida, o gel foi lavado rapidamente com água desionizada e tratado com uma solução contendo volumes iguais de $\mathrm{FeCl}_{3} 1 \%(\mathrm{~m} / \mathrm{v})$ e $\mathrm{K}_{3} \mathrm{Fe}(\mathrm{CN})_{6} 1 \%(\mathrm{~m} / \mathrm{v})$, por $10 \mathrm{~min}$ a temperatura ambiente. Após a coloração, o gel foi lavado com água desionizada, fixado em ácido acético $7 \%$ por 15 min e fotografado.

\subsubsection{Determinação das atividades de peroxidase}

Um dos métodos mais adequados para a avaliação das atividades de peroxidases, envolve a oxidação do guaiacol. A oxidação do guaiacol pela ação das peroxidases na presença de $\mathrm{H}_{2} \mathrm{O}_{2}$ forma o tetraguaiacol. As soluções de tetraguaiacol apresentam coloração castanho, a qual começa a desaparecer pouco tempo após a sua formação. A concentração dessa solução pode ser determinada espectrofotometricamente, se as absorbâncias forem determinadas rapidamente a $436 \mathrm{~nm}$ ou $470 \mathrm{~nm}$ (Maehly \& Chance, 1954; Chance \& Maehly, 1955; Bergmeyer et al., 1974). 
As atividades de POX foram avaliadas segundo Pütter (1974), com algumas modificações, em tampão fosfato $100 \mathrm{mM}$ (pH 7,0), contendo $100 \mu \mathrm{M}$ de $\mathrm{H}_{2} \mathrm{O}_{2}, 300 \mu \mathrm{M}$ de guaiacol e extrato de proteínas ( $10 \mu \mathrm{g}$ de proteína total), em um volume final de 1 $\mathrm{mL}$. A oxidação de guaiacol foi avaliada pelo aumento da absorbância a $470 \mathrm{~nm}$, durante 4 min. Para o branco, utilizou-se água desionizada no lugar de $\mathrm{H}_{2} \mathrm{O}_{2}$. A atividade específica de POX foi expressa como $\Delta \mathrm{A}_{470} \mathrm{mg}^{-1}$ proteína $\mathrm{min}^{-1}$. 


\section{RESULTADOS E DISCUSSÃO}

\subsection{Crescimento das plantas e colonização radicular}

Os resultados de massa de matéria fresca do sistema radicular (MFSR) e massa de matéria seca da parte aérea (MSPA) são apresentados na Tabela 1. Tanto a MFSR quanto a MSPA não diferiram significativamente (test $t, \mathrm{p}<0,05)$ entre os tratamentos não-inoculados e inoculados com FMAs, comparando-se dentro de cada época e de cada dose de P (Tabela 1). Resultados semelhantes foram obtidos por Lambais \& Mehdy (1993). A obtenção de plantas micorrizadas e não-micorrizadas, sob as mesmas condições ambientais, com biomassas semelhantes, permite a determinação do real efeito de FMAs na expressão gênica vegetal, como é discutido por Lambais \& Mehdy (1993, 1995, 1996).

A Figura 4, representa graficamente as variações da colonização das raízes de feijão pelos FMAs em condições de baixo e alto nível de $\mathrm{P}$ no solo, em diferentes épocas de amostragem. Os tratamentos controle não estão representados, já que não apresentaram colonização. A maior taxa de colonização foi obtida com 10 semanas após inoculação (SAI) pelo fungo G. clarum, 76 e $28 \%$ em condições de baixo e alto $\mathrm{P}$, respectivamente. Depois de $10 \mathrm{SAI}$, a porcentagem de colonização das raízes por $G$. intraradices foi de 6 e 3\%, em condições de baixo e alto $P$, respectivamente.

Embora não tenha havido incremento na produção de biomassa vegetal, diferenças significativas foram observadas no nível da colonização das raízes em condições favoráveis (baixo $\mathrm{P}$ ) e desfavoráveis (alto $\mathrm{P}$ ) à formação da simbiose. A obtenção de raízes com diferentes níveis de colonização, permite relacionar capacidade de colonização, sob diferentes níveis de $\mathrm{P}$ e regulação das possíveis vias de transdução 
de sinais em MAs, objeto de estudo do presente trabalho.

Tabela 1. Massa de matéria fresca do sistema radicular (MFSR) e massa de matéria seca da parte aérea (MSPA) de plantas de feijão não-inoculadas ou inoculadas com G. intraradices ou G. clarum, em condições de baixo (20 $\mathrm{mg} \mathrm{P}^{-1}$ ) ou alto (150 $\mathrm{mg}^{\mathrm{P} \mathrm{kg}}{ }^{-1}$ ) nível de fosfato. As amostras foram coletadas 4, 6, 8 e 10 semanas após a inoculação.

\begin{tabular}{|c|c|c|c|}
\hline $\begin{array}{l}\text { Semanas após } \\
\text { inoculação }\end{array}$ & Tratamento & $\begin{array}{c}\text { MFSR } \\
(\mathrm{g}) \\
\end{array}$ & $\begin{array}{c}\text { MSPA } \\
\text { (g) }\end{array}$ \\
\hline & & $20 \mathrm{mg} \mathrm{P} \mathrm{kg}^{-1}$ & \\
\hline \multirow[t]{3}{*}{4} & Não-inoculado & $3,28 \pm 0,56$ & $0,20 \pm 0,04$ \\
\hline & G. intraradices & $2,78 \pm 0,52$ & $0,18 \pm 0,03$ \\
\hline & G. clarum & $2,79 \pm 0,11$ & $0,20 \pm 0,05$ \\
\hline \multirow[t]{3}{*}{6} & Não-inoculado & $6,24 \pm 0,85$ & $1,34 \pm 0,19$ \\
\hline & G. intraradices & $6,38 \pm 1,13$ & $1,39 \pm 0,19$ \\
\hline & G. clarum & $6,20 \pm 1,39$ & $1,69 \pm 0,50$ \\
\hline \multirow[t]{3}{*}{8} & Não-inoculado & $22,68 \pm 0,76$ & $5,98 \pm 0,78$ \\
\hline & G. intraradices & $22,68 \pm 2,96$ & $5,17 \pm 0,73$ \\
\hline & G. clarum & $21,00 \pm 2,06$ & $5,80 \pm 0,78$ \\
\hline \multirow[t]{4}{*}{10} & Não-inoculado & $27,57 \pm 1,63$ & $8,32 \pm 0,33$ \\
\hline & G. intraradices & $28,33 \pm 2,89$ & $8,79 \pm 0,36$ \\
\hline & G. clarum & $24,02 \pm 0,48$ & $8,03 \pm 0,47$ \\
\hline & & $150 \mathrm{mg} \mathrm{P} \mathrm{kg}^{-1}$ & \\
\hline \multirow[t]{3}{*}{4} & Não-inoculado & $3,25 \pm 0,44$ & $0,23 \pm 0,08$ \\
\hline & G. intraradices & $2,40 \pm 0,11$ & $0,13 \pm 0,04$ \\
\hline & G. clarum & $2,59 \pm 0,32$ & $0,20 \pm 0,09$ \\
\hline \multirow[t]{3}{*}{6} & Não-inoculado & $7,86 \pm 0,61$ & $2,32 \pm 0,28$ \\
\hline & G. intraradices & $6,33 \pm 0,62$ & $2,12 \pm 0,30$ \\
\hline & G. clarum & $6,73 \pm 0,91$ & $1,82 \pm 0,42$ \\
\hline \multirow[t]{3}{*}{8} & Não-inoculado & $27,72 \pm 3,21$ & $8,55 \pm 0,90$ \\
\hline & G. intraradices & $25,44 \pm 3,07$ & $8,33 \pm 0,14$ \\
\hline & G. clarum & $20,23 \pm 1,93$ & $7,80 \pm 0,62$ \\
\hline \multirow[t]{3}{*}{10} & Não-inoculado & $21,79 \pm 1,02$ & $8,91 \pm 0,69$ \\
\hline & G. intraradices & $20,97 \pm 0,82$ & $9,31 \pm 0,46$ \\
\hline & G. clarum & $23,10 \pm 1,87$ & $9,91 \pm 0,23$ \\
\hline
\end{tabular}

Os dados são médias de 4 repetições \pm desvio padrão da média. 


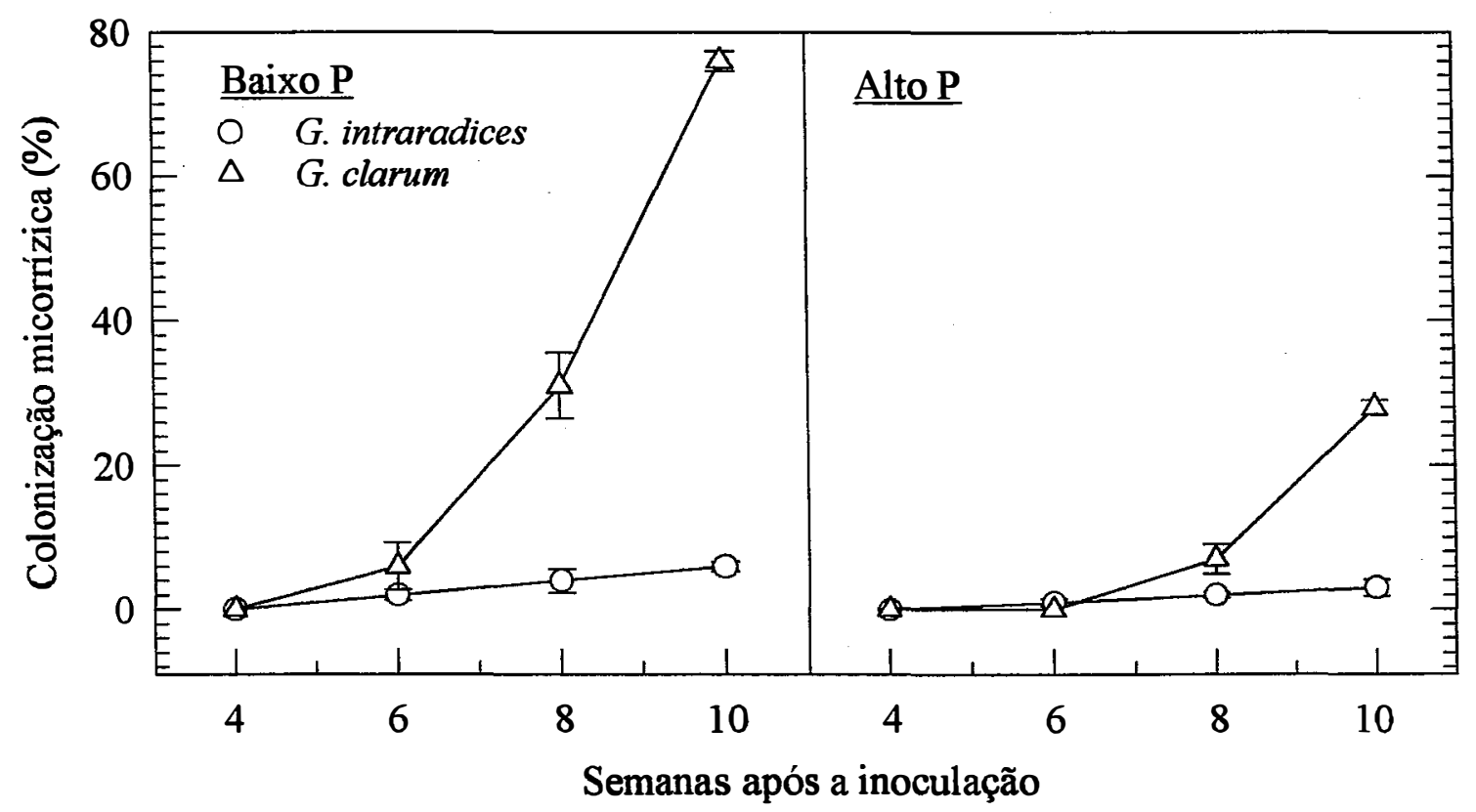

Figura 4. Porcentagem de colonização de raízes de feijoeiro inoculadas com $G$. intraradices ou G. clarum, em condições de baixo $\left(20 \mathrm{mg} \mathrm{P} \mathrm{kg}^{-1}\right)$ ou alto (150 $\mathrm{mg} \mathrm{P} \mathrm{kg}^{-1}$ ) nível de fosfato. As determinações foram realizadas 4, 6, 8 e 10 semanas após a inoculação. 


\subsection{Atividades enzimáticas de superóxido dismutase}

Os resultados das atividades de SOD dos diferentes tratamentos podem ser vistos na Figura 5. Em raizes colonizadas por G. clarum em condições de baixo $\mathrm{P}$ no solo, as atividades de SOD foram significativamente (teste $t \mathrm{p}<0,05$ ) maiores $(63 \%)$ do que em raízes do controle não-inoculado, 10 semanas após a inoculação (SAI). No entanto, em raízes colonizadas por G. intraradices, as atividades de SOD não diferiram estatisticamente do controle não-inoculado (teste $t \mathrm{p}<0,05$ ).

Em condições de alto $\mathrm{P}$, as atividades de SOD em raízes colonizadas por $G$. clarum, diferiram significativamente (teste $t \mathrm{p}<0,05$ ) do controle não-inoculado somente no início do desenvolvimento da simbiose (4 SAI). Nas demais épocas de colheita, diferenças significativas em relação ao controle não-inoculado, não foram observadas. Nessas mesmas condições, as atividades de SOD em raízes colonizadas por $G$. intraradices também não diferiram significativamente do controle não-inoculado.

O padrão de atividade de SOD observado em raízes colonizadas pelo fungo $G$. clarum, em condições favoráveis ao desenvolvimento da simbiose (baixo P no solo), é semelhante ao observado por Palma et al. (1993), no sistema Trifolium pratense-G. mosseae 10 SAI, e por Arines et al. (1994), no sistema Pisum sativum-G. mosseae avaliado aos 23 e 30 dias após a inoculação. Em ambos os casos, os autores observaram a indução das atividades de SOD. Ruiz Lozano et al. (1996) também observaram maior atividade de SOD em raízes micorrizadas do que em raízes não-micorrizadas. Martin et al. (1998), avaliando as atividades de SOD no sistema $T$. pratense-G. intraradices e $T$. pratense-G. mosseae, em diferentes épocas após a inoculação, observaram a indução somente 80 dias após a inoculação, em ambos os casos, em relação aos períodos anteriores (15, 30 e 50 dias após inoculação). No entanto, quando comparadas em cada época de colheita, não observaram diferenças significativas entre as atividades de SOD de raízes micorrizadas e não-micorrizadas. É importante salientar que nos estudos realizados por estes autores, as plantas inoculadas com FMAs foram cultivadas com concentrações de $\mathrm{P}$ menores em relação aos controles não-inoculados, favorecendo, desta maneira, a colonização das raízes pelos FMAs. Foi observado também que certas 


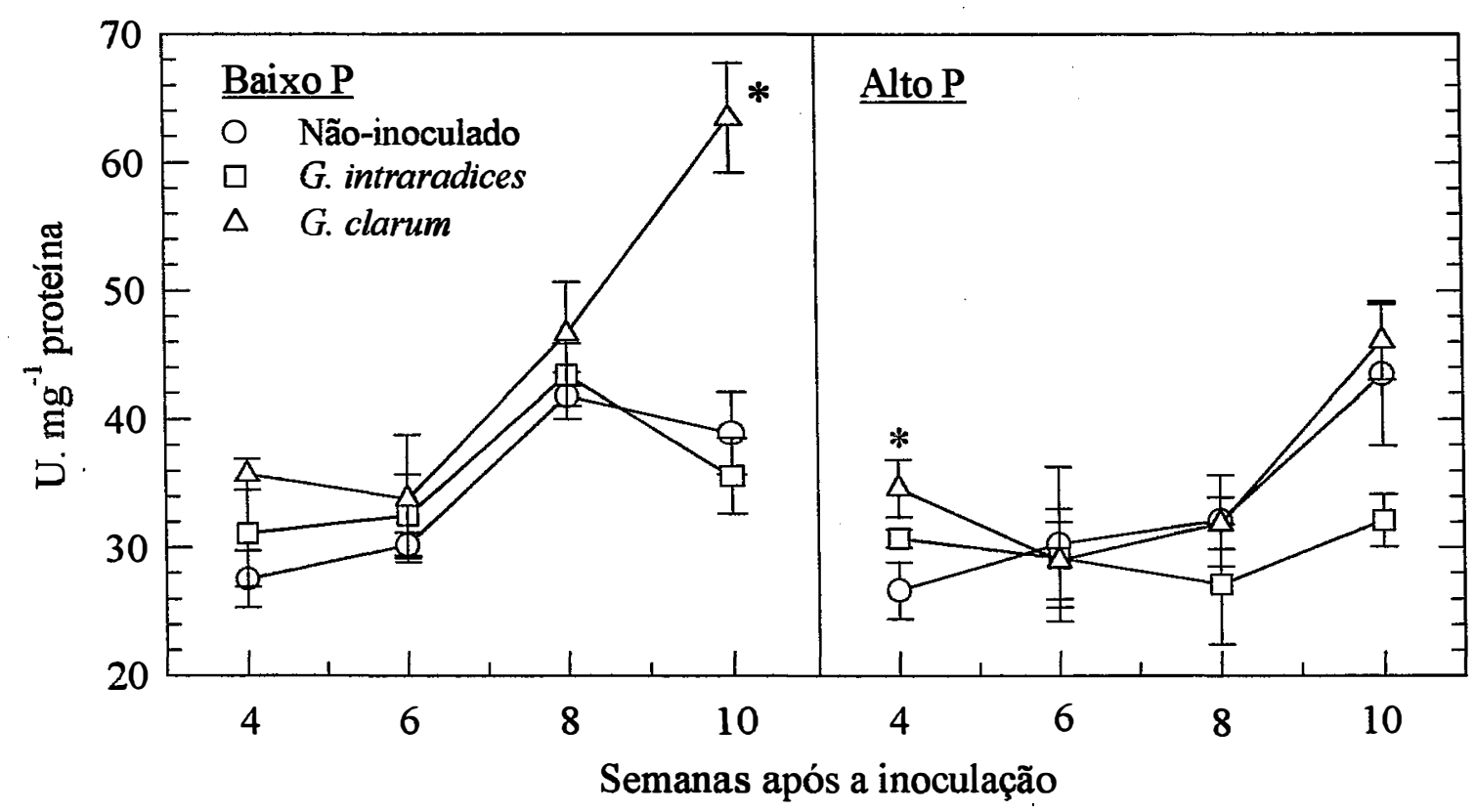

Figura 5. Atividades específicas de superóxido dismutases em raízes de feijoeiro nãoinoculadas ou inoculadas com G. intraradices ou G. clarum, em condições de baixo (20 mg P kg${ }^{-1}$ ) ou alto (150 $\mathrm{mg} \mathrm{P} \mathrm{kg}^{-1}$ ) nível de fosfato. As atividades foram determinadas 4, 6, 8 e 10 semanas após a inoculação. Os dados são médias de 4 repetições \pm desvio padrão da média. ${ }^{*}$, diferença significativa (teste $t, \mathrm{p}<0,05$ ), em relação ao controle não-inoculado, na mesma época de amostragem. 
isoformas são preferencialmente expressas em raízes micorrizadas, sugerindo que isoformas específicas podem ter papel importante na geração de $\mathrm{O}_{2}{ }^{\circ}$.

De maneira geral, os FMAs induzem atividades de SOD durante as fases mais tardias do desenvolvimento de MAs, em condições de baixo $\mathrm{P}$, contribuindo para a diminuição da concentração de $\mathrm{O}_{2}{ }^{\bullet-}$ em tecidos colonizados. Já em condições de alto $\mathrm{P}$, a indução de SOD pode ser observada somente no início do desenvolvimento de MAs, sugerindo a existência de incompatibilidade entre os simbiontes, nessas condições.

A produção de EAOs foi claramente demonstrada em interações incompativeis entre plantas e diferentes patógenos. Doke (1983), trabalhando com tecidos de tubérculo de batata e raças incompativeis de Phytophthora infestans, mostrou que a RH foi acompanhada pela produção de uma grande quantidade de $\mathrm{O}_{2}{ }^{\circ-}$ e que a adição de SOD no meio (convertendo $\mathrm{O}_{2}{ }^{\circ-}$ em $\mathrm{H}_{2} \mathrm{O}_{2}$ ) inibiu o desenvolvimento de $\mathrm{RH}$. Ádám et al. (1995) também observaram a indução de SOD na interação incompatível $P$. vulgaris-Ps. syringae, raça 1. Da mesma maneira, Vanacker et al. (1998) observaram um incremento de $150 \%$ nas atividades de SOD em relação aos controles não-inoculados numa interação incompatível entre a cevada e o fungo B. graminis (Alg-R).

Em função do padrão de atividades de SOD e da ausência de RH em MAs, é provável que o processo de elicitação seja, de alguma forma, atenuado durante a simbiose, evitando a geração de $\mathrm{O}_{2}{ }^{\circ}$. Alternativamente, os radicais $\mathrm{O}_{2}{ }^{\circ-}$ não são essenciais na transdução de sinais durante o crescimento fúngico intrarradicular.

\subsection{Atividades enzimáticas e caracterização isoenzimática de catalases}

Na Figura 6 são apresentados os resultados das atividades de CAT nos diferentes tratamentos. Em condições de baixo $\mathrm{P}$, em raízes colonizadas por G. clarum, as atividades de CAT foram 79\%, 65\% e 150\% maiores (teste $t, \mathrm{p}<0,05$ ) do que em raízes do controle não-inoculado, 4, 6 e $10 \mathrm{SAI}$, respectivamente. Em condições de alto $\mathrm{P}$, as atividades de CAT em raizes colonizadas por G. clarum foram $357 \%$ maiores 4 SAI e 80 $\%$ menores, $8 \mathrm{SAI}$, sendo essas diferenças significativas quando comparadas com o controle não-inoculado (teste $t \mathrm{p}<0,05$ ). Em raízes colonizadas por $G$. intraradices, em 


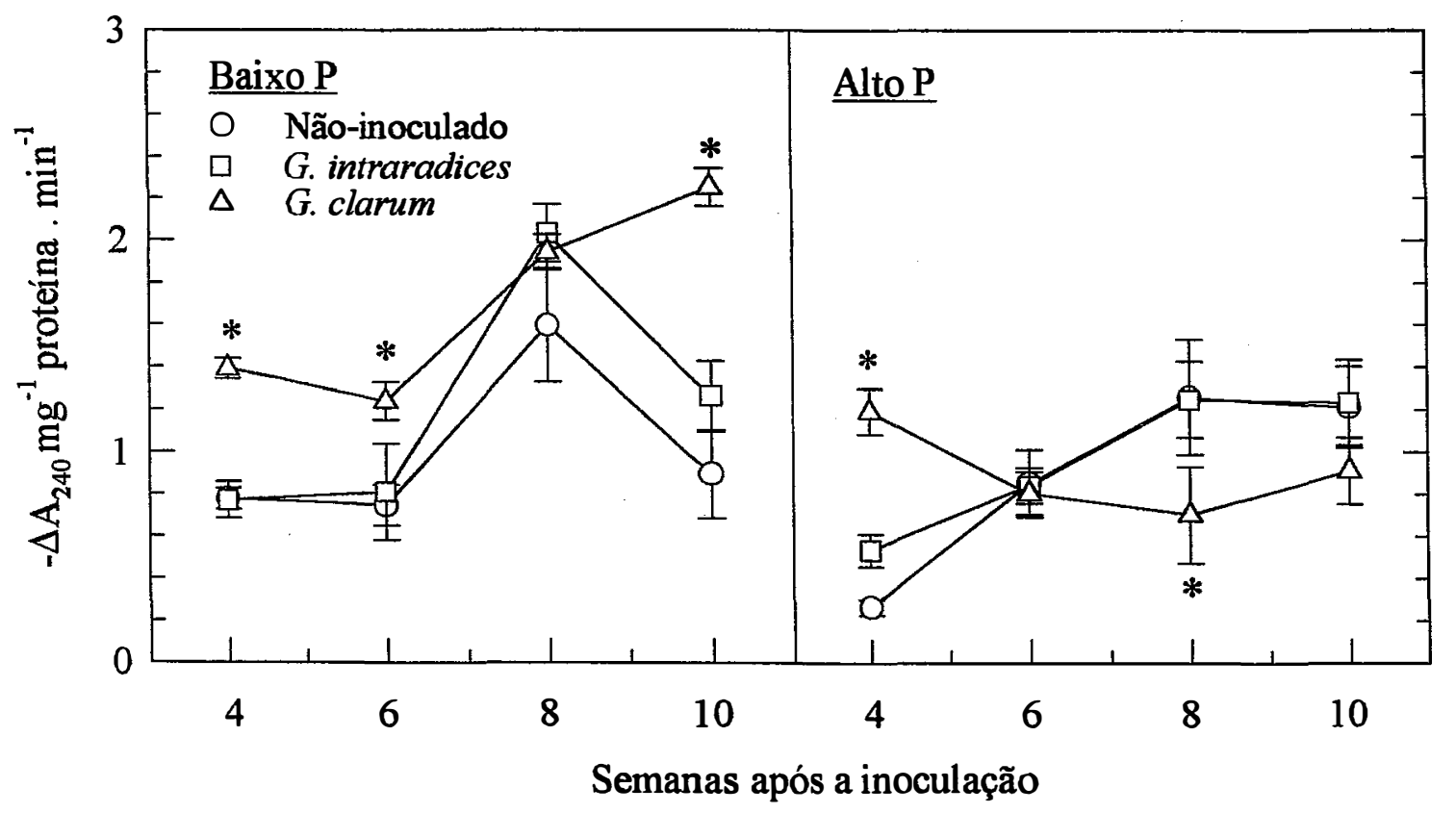

Figura 6. Atividades específicas de catalases em raízes de feijoeiro não-inoculadas ou inoculadas com $G$. intraradices ou $G$. clarum, em condições de baixo (20 mg P $\mathrm{kg}^{-1}$ ) ou alto (150 mg P kg$\left.{ }^{-1}\right)$ nível de fosfato. As atividades foram determinadas 4, 6, 8 e 10 semanas após a inoculação. Os dados são médias de 4 repetições \pm desvio padrão da média. *, diferença significativa (teste $t, \mathrm{p}<0,05$ ), em relação ao controle não-inoculado, na mesma época de amostragem. 
condições de baixo e alto $\mathrm{P}$, as atividades de CAT não diferiram significativamente do controle não-inoculado (teste $t \mathrm{p}<0,05$ ).

Pela primeira vez foram avaliados os padrões de atividades de CATs em MAs e os dados obtidos sugerem que o $\mathrm{H}_{2} \mathrm{O}_{2}$ poderia estar envolvido no processo de sinalização entre os simbiontes durante a colonização das raízes, já que a indução das atividades de CAT está associada à rápida colonização das raízes pelo fungo mais infectivo, $G$. clarum, em condições favoráveis (baixo $\mathrm{P}$ ). A degradação de $\mathrm{H}_{2} \mathrm{O}_{2}$ pelas CATs poderia evitar a ativação de genes de defesa (Wu et al., 1997), facilitando o crescimento fúngico intrarradicular. Indução significativa das atividades de CAT também foi observada na interação patogênica compativel, H. vulgare-B. graminis Alg-S (Vanacker et al., 1998), sugerindo que nessa interação estaria ocorrendo a degradação de $\mathrm{H}_{2} \mathrm{O}_{2}$ impedindo a ativação dos mecanismos de defesa e favorecendo o crescimento fúngico.

Com relação aos padrões de atividades de CAT em condições desfavoráveis ao desenvolvimento da simbiose (alto P no solo), observou-se indução inicial e posterior supressão das atividades de CAT, o que poderia resultar em acúmulo de $\mathrm{H}_{2} \mathrm{O}_{2}$ e conseqüente ativação do sistema de defesa vegetal, explicando em parte, o baixo nível de colonização pelo FMA mais infectivo em condições de alto P. A supressão das atividades de CAT em interações incompatíveis ( $P$. vulgaris-Ps. syringae, raça 1), também foi observada por Ádám et al. (1995) e Milosevic \& Slusarenko (1996). No entanto, nessas interações patogênicas foram observadas respostas de hipersensibilidade, o que não é evidente em MAs. Esses dados sugerem que as MAs possuem mecanismos eficazes para atenuar as respostas de defesa vegetal, os quais poderiam estar atuando sobre mensageiros secundários.

A alteração da expressão de vários genes vegetais tem sido observada durante o desenvolvimento de MAs, incluindo genes envolvidos na defesa das plantas contra a infecção por microrganismos patogênicos (Spanu \& Bonfante-Fasolo, 1988; Lambais \& Mehdy, 1993; Vierheilig et al., 1994; Volpin et al., 1994; Fries et al. 1996; Mohr et al., 1998). Para alguns genes, essa indução ocorre localizadamente, em células específicas do tecido cortical e só pode ser detectada in situ (Lambais \& Mehdy, 1998). Além da indução localizada, tem sido observada também a ocorrência de supressão da expressão 
de genes relacionados ao sistema de defesa vegetal. Em condições semelhantes ao nosso experimento, Lambais \& Mehdy (1993) observaram supressão significativa das atividades de quitinases e $\beta$-1,3-glicanases em raízes de feijão colonizadas por $G$. intraradices em condições de baixo P. Em condições de alto $\mathrm{P}$, foi observada uma atenuação dessa supressão. No entanto, indução localizada de certas isoformas pode ocorrer dependendo do nível de P (Lambais \& Mehdy, 1998). David et al. (1998) demonstraram, usando plantas de fumo inoculadas com G. intraradices, que o promotor de um gene codificando uma quitinase ácida é induzido em raizes micorrizadas em condições de alto $P$, mas não em condições de baixo $P$. A não ativação de certos genes e a supressão de outros sugerem mecanismos de transdução de sinais diferenciados em MAs.

As atividades de CAT em géis de poliacrilamida não-desnaturante podem ser vistas na Figura 7. Somente uma isoforma de CAT em raizes de feijão foi observada, utilizando separação eletroforética unidimencional, nos diferentes tratamentos. No entanto, a possibilidade de existência de múltiplas isoformas com a mesma massa molecular não pode ser desconsiderada. A determinação da existência de outras isoformas de CAT em raizes de feijão poderia ser feita através de focalização isoelétrica. Braber $^{1}$ (1980), citado por Havir \& Mchale (1987), também observou uma única isoforma de CAT em folhas de feijão. Em Ricinus communis, 2 isoenzimas de CAT foram observadas, mas somente uma sendo expressa em raizes (Ota et al., 1992).

A indução das atividades de CAT em raízes micorrizadas por G. clarum pode ser também observada nos géis, confirmando os resultados dos ensaios com proteína em solução. As diferenças entre os tratamentos são mais notórias 4 semanas após a inoculação. Pode ser observado também que, independente da presença de FMAs, as atividades de CAT são suprimidas em condições de alto $\mathrm{P}$, comparado com baixo $\mathrm{P}$. Essa supressão pelo alto nível de $\mathrm{P}$ é mais acentuada no início do desenvolvimento da planta.

${ }^{1}$ BRABER, J.M. Catalase e peroxidase in primary bean leaves during development and senescence. Z. Pflanzenphysiol, v.97, p.135-144, 1980. 


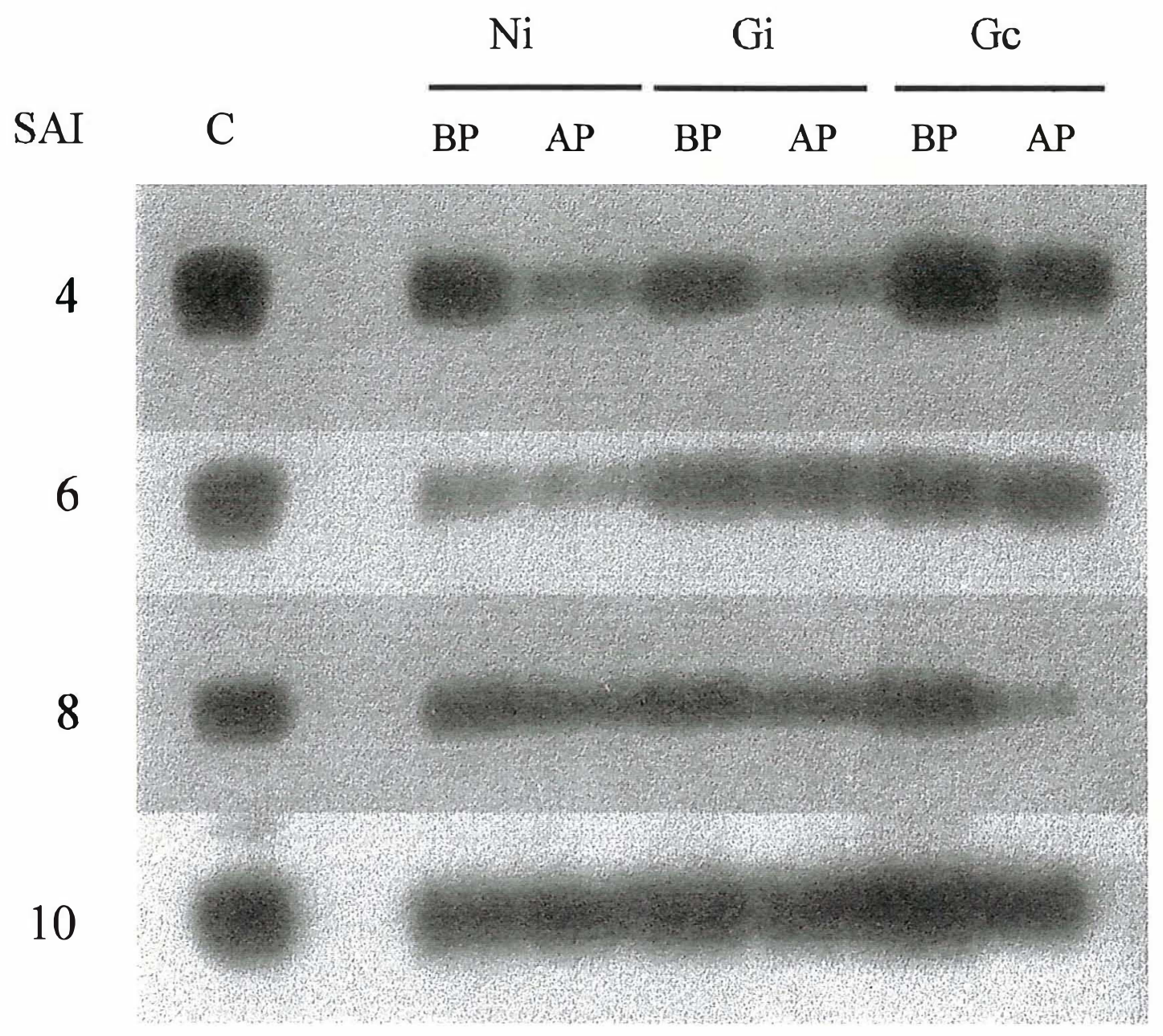

Figura 7. Caracterização isoenzimática de catalases em gel de poliacrilamida nãodesnaturante. A eletroforese foi realizada com quantidades iguais de proteína total (30 ug) de raízes de feijoeiro não-inoculadas (Ni) ou inoculadas por ( $\mathrm{s}$. intraradices (Gi) ou G. clarum (Gc), em condições de baixo (BP = 20 mg P $\left.\mathrm{kg}^{-1}\right)$ ou alto $\left(\mathrm{AP}=150 \mathrm{mg} \mathrm{P} \mathrm{kg}^{-1}\right)$ nível de fosfato. SAI, semanas após a inoculação; C, controle positivo (duas unidades de catalase de fígado de boi). 


\subsection{Atividades enzimáticas de peroxidase}

Os resultados das atividades de POX dos diferentes tratamentos são apresentados na Figura 8. Em condições de baixo $\mathrm{P}$, as atividades de $\mathrm{POX}$, em raízes colonizadas por G. clarum foram $136 \%$ maiores e $58 \%$ menores (teste $t \mathrm{p}<0,05$ ) do que em raízes do controle não-inoculado, 4 e $10 \mathrm{SAI}$, respectivamente. Em condições de alto $\mathrm{P}$, supressão significativa de $35 \%$ em relação ao controle não-inoculado (teste $t \mathrm{p}<0,05$ ) foi observada $10 \mathrm{SAI}$. Em raizes colonizadas por $G$. intraradices, em condições de baixo e alto $\mathrm{P}$, as atividades de POX não diferiram significativamente do controle não- inoculado (teste $t$ $\mathrm{p}<0,05)$.

Os padrões de atividades de POX em condições de baixo $\mathrm{P}$ apresentaram indução transiente nas raizes colonizadas pelo fungo mais infectivo, G. clarum, com posterior supressão. A indução transiente de POX em raízes micorrizadas seguida de supressão já foi observada anteriormente nas interações A. porrum-G. mosseae (Spanu \& BonfanteFasolo, 1988) e Z. mays-G. intraradices (Fries et al., 1996). Isso sugere que o FMA induz uma resposta de defesa inicial por parte da planta (Dumas-Gaudot et al., 1994), mas, posteriormente ocorre supressão dessa resposta, favorecendo o desenvolvimento da simbiose. Em contraste, McArthur \& Knowles (1992) não observaram supressão das atividades de POX em raízes de batata em condições de baixo e alto P no solo. Foi observado, no entanto, menor atividade de POX em raízes sob baixo $\mathrm{P}$ quando comparadas com raizes sob alto P (McArthur \& Knowles, 1993). Mathur \& Vyas (1995) observaram aumentos das atividades de POXs na interação Ziziphus-Glomus fasciculatum, devido provavelmente ao fato de certas isoformas de POX serem preferencialmente expressas em MAs.

Com base nos resultados obtidos, é provável que a atividade catalítica de degradação de $\mathrm{H}_{2} \mathrm{O}_{2}$ não seja a principal função de POXs em MAs e que elas não estejam envolvidas na transdução de sinais. POX poderia estar possivelmente envolvida no reforço da parede celular vegetal (Bradley et al., 1992; Bonatti et al., 1994; Intapruk et al., 1994). 


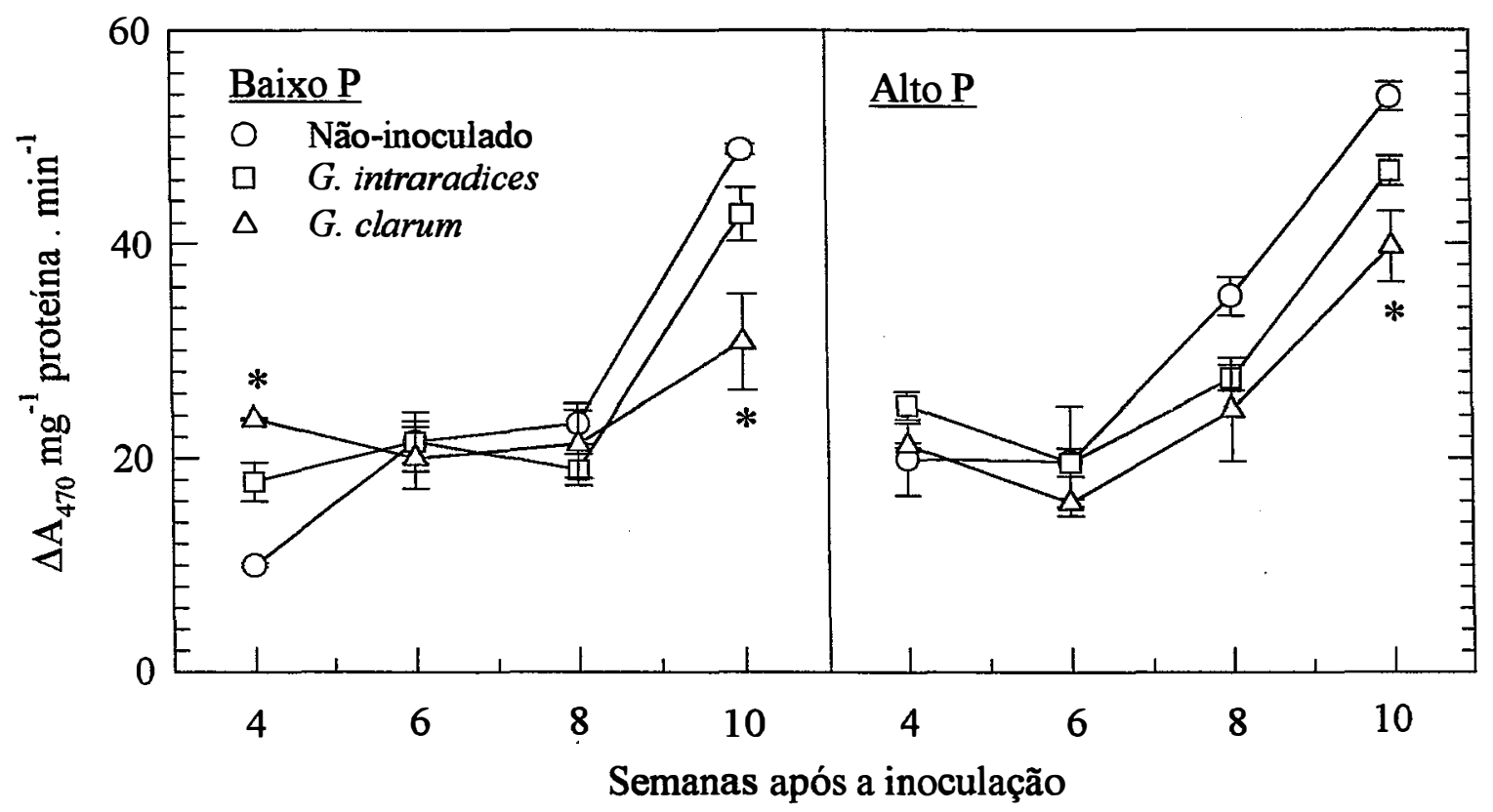

Figura 8. Atividades específicas de peroxidases em raizes de feijoeiro não-inoculadas ou inoculadas por G. intraradices ou G. clarum, em condições de baixo (20 mg P $\left.\mathrm{kg}^{-1}\right)$ ou alto $\left(150 \mathrm{mg} \mathrm{P} \mathrm{kg}^{-1}\right)$ nível de fosfato. As atividades foram determinadas 4, 6, 8 e 10 semanas após a inoculação. Os dados são médias de 4 repetições \pm desvio padrão da média. *, diferença significativa (teste $t$, p<0,05), em relação ao controle não-inoculado, na mesma época de amostragem. 


\section{CONCLUSÕES}

Através dos resultados obtidos, nas condições em que este experimento foi realizado, conclui-se que:

a) As atividades de superóxido dismutase, catalases e peroxidase avaliadas em raízes colonizadas pelo fungo mais infectivo, Glomus clarum, apresentaram alterações significativas em relação aos controles não-inoculados, enquanto que, nenhuma alteração significativa na atividade dessas enzimas foi observada em raízes colonizadas pelo fungo menos infectivo, Glomus intraradices, nas diferentes épocas de amostragem.

b) Os dados sugerem que, durante o desenvolvimento de micorrizas arbusculares, catalases poderiam participar da degradação de $\mathrm{H}_{2} \mathrm{O}_{2}$, evitando seu acúmulo e a possível ativação de genes de defesa, facilitando assim, o crescimento fúngico intrarradicular. 


\section{REFERÊNCIAS BIBLIOGRÁFICAS}

ÁDÁM, A.L.; BESTWICK, C.S.; BARNA, B.; MANSFIELD, J.W. Enzymes regulating the accumulation of active oxygen species during the hypersensitive reaction of bean to Pseudomonas syringae pv. phaseolicola. Planta, v.197, n.2, p.240-249, 1995.

AEBI, H. Catalase in vitro. Methods in Enzimology, v.105, p.121-126, 1984.

ALSKOG, G.; HUSS-DANELL, K. Superoxide dismutase, catalase and nitrogenase activities of symbiotic Frankia (Alnus incana) in response to different oxygen tensions. Physiologia Plantarum, v.99, n.2, p.286-292, 1997.

ARINES, J.; QUINTELA, M.; VILARIÑO, A.; PALMA, J. Protein patterns and superoxide dismutase activity in non-mycorrhizal and arbuscular mycorrhizal Pisum sativum L. plants. Plant and Soil, v.166, n. 1, p.37-45, 1994.

BAKER, C.J.; ORLANDINI, E.W.; MOCK, N.M. Harpin, an elicitor of the hypersensitive response in tobacco caused by Erwinia amylovora, elicits active oxygen production in suspension cells. Plant Physiology, v.102, n.4, p.1341-1344, 1993.

BERGMEYER, H.U.; GAWEHN, K.; GRASSL, M. Enzymes as biochemical reagents. In: BERGMEYER, H.U. (Ed.) Methods of enzymatic analysis. 2 ed. New York: Academic Press, 1974. p.494-495.

BERGMEYER, H.U.; KLOTZCH, H; MÖLLERIN, H.; NELBÖCK-HOCHSTETTR, M.; BEAUCAMP, K. Biochemical reagents. In: BERGMEYER, H.U. (Ed.) Methods of enzymatic analysis, New York: Academic Press, 1963. p.990-991.

BONATTI, P.M.; LORENZINI, G.; FORNASIERO, R.B.; NALI, C.; SGARBI, E. Cytochemical detection of cell wall bound peroxidase in rust infected broad bean leaves. Journal of Phytopathology, v. 140, n.4, p.319-325, 1994.

BOLAN, N.S. A critical review on the roll of mycorrhizal fungi in the uptake of phosphorus by plants. Plant and Soil, v.134, n.2, p.189-207, 1991. 
BONFANTE, P.; PEROTTO, S. Strategies of arbuscular mycorrhizal fungi when infecting host plants. New Phytologist, v.130, n.1, p.3-21, 1995.

BONFANTE-FASOLO, P.; PEROTTO, S. Plants and endomycorrhizal fungi: the cellular and molecular basis of their interaction. In: VERMA, D.P.S. Molecular signals in plant-microbe comunications. London: CRC Press, 1992. p.445-470.

BOWLER, C.; VAN MONTAGU, M.; INZÉ, D. Superoxide dismutase and stress tolerance. Annual Review of Plant Physiology and Plant Molecular Biology, v.43, p.83-116, 1992.

BOWLES, D.J. Defence-related proteins in higher plants. Annual Review of Biochemistry, v.59, p.873-907, 1990.

BRADFORD, M.M. A rapid and sensitive method for the quantitation of microgram quantities of protein utilizing the principle of protein-dye binding. Analytical Biochemistry, v.72, n.1-2, p.248-254, 1976.

BRADLEY, D.J.; KJELLBOM, P.; LAMB, C.J. Elicitor-and wound-induced oxidative cross-linking of a proline-rich plant cell wall structural protein: a novel, rapid plant defense response. Cell, v.70, n.1, p.21-30, 1992.

CAKMAK, I.; HORST, W.J. Effect of aluminium on lipid peroxidation, superoxide dismutase, catalase, and peroxidase activities in root tips of soybean (Glycine max). Physiologia Plantarum, v.83, n.3, p.463-468, 1991.

CHANCE, B.; MAEHLY, A.C. Assay of catalases and peroxidases. Methods in Enzymology, v.2, p.764-775, 1955.

CHANDRA, S.; LOW, P.S. Role of phosphorylation in elicitation of the oxidative burst in cultured soybean cell. Proceeding of National Academic of Science USA, v.92, p. 4120-4123, 1995.

CHEN, Z.; SILVA, H.; KLESSIG, D.F. Active oxygen species in the induction of plant sistemic acquired resistance by salicylic acid. Science, v. 262, n.5141, p. 18831886, 1993.

DANGL, J.L.; DIETRICH, R.A.; RICHBERG, M.H. Death don't have no mercy: cell death program in plant-microbe interactions. Plant cell, v.8, n.10, p.1793-1807, 1996.

DAVID, R.; ITZHAKI, H.; GINZBERG, I.; GAFNI, Y.; GALILI, G.; KAPULNIK, Y. Suppresion of tobacco basic chitinase gene expression in response to colonization by the arbuscular mycorrhizal fungus Glomus intraradices. Molecular Plant Microbe Interaction, v. 1 1, n.6, p.489-497, 1998. 
DOKE, $\mathrm{N}$. Involvement of superoxide anion generation in the hypersensitive response of potato tuber tissues to infection with an incompatible race of Phytophthora infestans and to the hiphal wall components. Physiological Plant Pathology, v.23, n.3, p. 345-357, 1983.

DOKE, N.; MIURA, L.M. In vitro activation of NADPH-dependent $\mathrm{O}_{2}^{-}$generating system in a plasma membrane-rich fraction potato tuber tissues by treatment with na elicitor from Phytophthora infestans or with digitonin. Physiological and Molecular Plant Pathology, v.46, p.17-28, 1995.

DRUMM, H.; SCHOFER, P. Effect of phytochrome on development of catalase activity and isoenzyme pattern in mustard (Sinapsis alba L.) seedlings. A reinvestigation. Planta, v.120, p.13-30, 1974.

DUMAS-GAUDOT, E.; GRENIER, J.; FURLAN, V.; ASSELIN, A. Chitinase, chitosanase and $\beta$-1,3-glucanase activities in Allium and Pisum roots colonized by Glomus species. Plant Science, v.84, n.1, p.17-24, 1992.

DUMAS-GAUDOT, E.; GUILLAUME, P.; TAHIRI-ALAOVI, A.; GIANINAZZIPEARSON, V.; GIANINAZZI, S. Changes in polypeptide patterns in tobacco roots by two Glomus species. Mycorrhiza, v.4, n.5, p.215-221, 1994.

FLOHÉ, L.; ÖTING, F. Superoxide dismutase assays. Methods in Enzymology, v. 105, p.93-104, 1984.

FOSTER, J.G.; HESS, J.L. Responses of superoxide dismutase and glutathione reductase activities in cotton leaf tissue exposed to an atmosphere enriched in oxygen. Plant Physiology, v.66, n.3, p.482-487, 1980.

FRIDOVICH, I. Superoxide dismutases. Advances in Enzymology and Related Areas of Molecular Biology, v.58, p.61-73, 1986.

FRIES, L.M.; PACOVSKY, R.S.; SAFIR, G.R. Expression of isoenzymes altered by both Glomus intraradices colonization and formononetin application in corn (Zea mays L.) roots. Soil Biology and Biochemestry, v.28, n.8, p.981-988, 1996.

FRUGOLI, J.A.; ZHONG, H.H.; NUCCIO, M.L.; McCOURT, P.; McPEEK, M.A.; THOMAS, T.L.; McCLUNG, C.R. Catalase is encoded by a multigene family in Arabidopsis thaliana (L.) Heynh. Plant Physiology, v.112, n. 1, p.327-336, 1996.

FRY, S.C. Cross-linking of matrix polymers in the growing cell wall of angiosperms. Annual Review of Plant Physiology, v.37, p. 165-186, 1986.

GERDEMANN, J.W.; NICOLSON, T.H. Spores of mycorrhizal Endogone species extracted from soil by wet sieving and decanting. Transactions of the British Mycological Society, v.46, n.2, p.235-244, 1963 
GIANINAZZI, S. Vesicular-arbuscular (endo-) mycorrhizas: cellular, biochemical and genetic aspects. Agriculture Ecosystems Environment, v.35, n.2-3, p.105-119, 1991.

GIANINAZZI-PEARSON, V. Morphofunctional compatibility in interactions between roots and arbuscular endomycorrhizal fungi: molecular mechanisms, genes and gene expression. In: KOHMOTO, K.; SINGH, U.S.; SINGH, R.P. (Eds.) Pathogenesis and host specificity in plant diseases. Oxford: Pergamon, 1995, v.2, cap.15, p.251263.

GIANINAZZI-PEARSON, V. Plant cell responses to arbuscular mycorrhizal fungi: Getting to the roots of the symbiosis. Plant Cell, v.8, n.10, p.1871-1883, 1996.

GIANINAZZI-PEARSON, V.; DUMAS-GAUDOT, E.; GOLLOTE, A.; TAHIRIALAOUI, A.; GIANINAZZI, A. Cellular and molecular defence-related root responses to invasion by arbuscular mycorrhizal fungi. New Phytologist, v.133, n.1, p.45-57, 1996.

GIOVANNETTI, M.; MOSSE, B. An evaluation of techniques for measuring vesicular arbuscular mycorrhizal infection in roots. New Phytologist, v.84, n.3, p.489-500, 1980.

GOGORCENA, Y; ITURB-ORMAETXE, I.; ESCUDERO, P.R.; BECANA, M. Antioxidant defenses against activated oxygen in pea nodules subjected to water stress. Plant Physiology, v.108, n.2, p.753-759, 1995.

HAMMOND-KOSACK, K.E.; JONES, J.D.G. Resistance gene-dependent plant defense responses. Plant Cell, v.8, n. 10, p.1773-1791, 1996.

HARLEY, J.L.; SMITH, S.E. Mycorrhizal symbiosis. London: Academic Press, 1983. $483 \mathrm{p}$.

HAVIR, E.A.; McHALE, N.A. Biochemical and developmental characterization of multiple forms of catalase in tobacco leaves. Plant Physiology, v.84, n.2, p.450455, 1987.

HOAGLAND, R.E. Biochemical responses of plants to pathogens. In: HOAGLAND, R.E. (Ed.) Microbes and microbial products as herbicides. Washington: Americal Chemical Society, 1990, p.87-113.

INTAPRUK, C.I.; TAKANO, M.; SHINMYO, A. Nucleotide sequence of a new cDNA for peroxidase from Arabidopsis thaliana. Plant Physiology, v.104, n.1, p.285-286, 1994. 
ISHIGE, F.; MORI, H.; YAMAZAKI, K.; IMASEKI, H. Identification of a basic glycoprotein induced by ethylene in primary leaves of Azuki bean (Vigna angularis) as a cation peroxidase. Plant Physiology, v.101, n.1, p.193-199, 1993.

KAUSS, H.; JEBLICK, W. Pretreatment of parsley suspension cultures with salicylic acid enhances spontaneous and elicited production of $\mathrm{H}_{2} \mathrm{O}_{2}$. Plant Physiology, v.108, n.3, p.1171-1178, 1995.

KOIDE, R.T.; LI, M. On host regulation of the vesicular-arbuscular mycorrhizal symbiosis. New Phytologist, v.114, n. 1, p.59-74, 1990.

KOIDE, R.T.; SCHREINER, R.P. Regulation of the vesicular-arbuscular mycorrhizal symbiosis. Annual Review of Plant Physiology and Plant Molecular Biology, v.43, p.557-581, 1992.

LAMB, C.J.; LAWTON, M.A.; DRON, M.; DIXON, R.A. Signals and transduction mechanisms for activation of plant defenses against microbial attack. Cell, v.56, n.2, p.215-224, 1989.

LAMB, C.J.; DIXON, R.A. The oxidative burst in plant disease resistance. Annual Review of Plant Physiology and Plant Molecular Biology, v. 48, p.251-275, 1997.

LAMBAIS, M.R. Aspectos bioquímicos e moleculares da relação fungo-planta em micorrizas arbusculares. In: SIQUEIRA, J.O. Avanços em fundamentos e aplicações de micorrizas. Lavras: UFLA, 1996. cap.2, p.5-38.

LAMBAIS, M.R.; MEHDY, M.C. Suppression of endochitinase, $\beta-1,3$-endoglucanase, and chalcone isomerase expression in bean vesicular-arbuscular mycorrhizal roots under different soil phosphate conditions. Molecular Plant-Microbe Interactions, v.6, n.1, p.75-83, 1993.

LAMBAIS, M.R.; MEHDY, M.C. Differential expression of defense-related genes in arbuscular mycorrhiza. Canadian Journal of Botany, v.73, supl.1, p.533-540, 1995.

LAMBAIS, M.R.; MEHDY, M.C. Soybean roots infected by Glomus intraradices strains differing in infectivity exhibit differential chitinase and $\beta$-1,3-glucanase expression. New Phytologist, v. 134, n.3, p. 531-538, 1996.

LAMBAIS, M.R.; MEHDY, M.C. Spatial distribution of chitinases and $\beta$-1,3-glucanase transcripts in bean arbuscular mycorrhizal roots under low anh high soil phosphate conditions. New Phytologist, v. 140, 1998 (No prelo). 
LEGENDRÉ, L.; HEINSTEIN, P.F.; LOW, P.S. Evidence for participation of GTPbinding proteins in elicitation of the rapid oxidative burst in cultured soybean cells. Journal of Biological Chemistry, v.267, n.28, p.20140-20147, 1992.

LÉON, J.; LAWTON, M.A.; RASKIN, I. Hydrogen peroxide stimulates salicylic acid biosynthesis in tobacco. Plant Physiology, v.108, n.4, p.1673-1678, 1995.

LEITE, B; RONCATO, L.D.B.; PASCHOLATI, S.F.; LAMBAIS, M.R. Reconhecimento e transdução de sinais moleculares em interações planta-fungos patógenos. Revisão Anual de Patologia de Plantas, v.5, p.235-281,1997.

LEVINE, A.; TENHAKEN, R.; DIXON, R.; LAMB, C. $\mathrm{H}_{2} \mathrm{O}_{2}$ from oxidative burst orchestrates the plant hypersensitive disease resistance response. Cell, v.79, n.4, p.583-593, 1994.

LOW, P.S.; MERIDA, J.R. The oxidative burst in plant defence: Function and signal transduction. Physiologia Plantarum, v.96, n.3, p.533-542, 1996.

LUCAS, J.A. Plant pathology and plant pathogens. 3. ed. Oxford: The Blackwell Science, 1998. cap.9, p.140-165.

MAEHLY, A.C.; CHANCE, B. The assay of catalases and peroxidases. In: GLICK, D. (Ed.) Methods of biochemical analysis. New York: Interscience Publishers, 1954. v.1, p.354-408.

MARTIN, J.; GARCIA-ROMERA, I.; OCAMPO, J.A.; PALMA, J.M. Superoxide dismutase and arbuscular mycorrhizal fungi: Relationship between the isoenzyme pattern and the colonizing fungus. Symbiosis, v.24, n.2, p.247-258, 1998.

MATHUR, N.; VYAS, A. Changes in isozyme patterns of peroxidase and polyphenol oxidase by VAM fungi in roots of Ziziphus species. Journal of Plant Physiology, v.145, n.4, p.498-500, 1995.

McARTHUR, D.A.J.; KNOWLES, N.R. Resistance responses of potato to vesicular arbuscular mycorrhizal fungi under varying abiotic phosphorus levels. Plant Physiology, v.100, n. 1, p.341-351, 1992.

McARTHUR, D.A.J.; KNOWLES, N.R. Influence of vesicular arbuscular mycorrhizal fungi on the response of potato to phosphorus deficiency. Plant Physiology, v.101, n. 1, p.147-160, 1993.

MEHDY, M.C. Active oxygen species in plant defense against pathogens. Plant Physiology, v.105, n.2, p.467-472, 1994. 
MEHDY, M.C.; SHARMA, Y.K.; SATHASIVAN, K.; BAYS, N.W. The role of activated oxygen species in plant disease resistance. Physiologia Plantarum, v.98, p.365-374, 1996.

MILOSEVIC, N.; SLUSARENKO, A.J. Active oxygen metabolism and lignification in the hypersensitive response in bean. Physiological and Molecular Plant Pathology, v.49, n.3, p.143-158, 1996.

MOHR, V.; LANGE, J.; BOLLER, T.; WIEMKEN, A.; VÖGELI-LANGE, R. Plant defence genes are induced in the pathogenic interaction between bean roots and Fusarium solani, but not in the symbiotic interaction with the arbuscular mycorrhizal fungus Glomus mosseae. New Phytologist, v.138, n.4, p. 589-598, 1998.

MORTON, J.N.; BENNY, G.L. Revised classification of arbuscular mycorrhizal fungi (Zygomycetes): a new order Glomales, two new suborders, Glomineae and Gigasporineae, and two new families, Acaulosporaceae and Gigasporaceae, with an emendation of Glomaceae. Mycotaxon, v.37, p.471-491, 1990

NEUENSCHWANDER, U.; VERNOOIJ, B.; FRIEDRICH, L.; UKNESS, S.; KESMANN, H.; RYALS, J. Is hydrogen peroxide a second messenger of salicylic acid in systemic acquired resistance? Plant Journal, v.8, n.2, p.227-233, 1995.

NÜRNBERGER, T.; NENNSTIEL, D.; JABS, T.; SACKS, W.R.; HAHLBROCK, K.; SCHEEL, D. High affinity binding of a fungal oligopeptide elicitor to parsley plasma membranes triggers multiple defense responses. Cell, v.78, n.3, p.449-460, 1994.

OTA, Y.; ARIO, T.; HAYASHI, K.; NAKAGAWA, T.; HATTORI, T.; MAESHIMA, M. ASAHI, T. Tissue-specific isoforms of catalase subunitis in castor bean seedlings. Plant Cell Physiology, v.33, n.3, p.225-232, 1992.

PALMA, M.J.; ANGELES LONGA, M.; DEL RIO A.L.; ARINES, J. Superoxide dismutase in vesicular-arbuscular mycorrhizal red clover plants. Physiologia Plantarum, v.87, n.1, p.77-83, 1993.

PALMA, J.M.; GARRIDO, M.; RODRIGUEZ-GARCIA, M.I.; del RIO, L.A. Peroxisome proliferation and antioxidative stress mediated by activated oxygen species in plant peroxisomes. Archives of Biochemistry and Biophysics, v.287, n.1, p.68-74, 1991.

PASCHOLATI, S.F.; LEITE, B. Hospedeiro: mecanismos de resistência. In: BERGAMIN FILHO, A.; KIMATI, H.; AMORIN, L. (Ed.) Manual de fitopatologia: principios e conceitos. 3. ed. São Paulo: Agronômica Ceres, 1995. v.1, cap.22, p.417-453. 
PHILLIPS, J.M.; HAYMAN, D.S. Improved procedures for clearing roots and staining parasitic and vesicular-arbuscular mycorrhizal fungi for rapid assessment of infection. Transactions of the British mycolical Society, v.55, n.1, p.158-161, 1970.

PINHEIRO, R.G.; RAO, M.V.; PALIYATH, G.P.; MURR, D.P.; FLETCHER, R.A. Changes in activities of antioxidant enzymes and their relationship to genetic and paclobutrazol-induced chilling tolerance of maize seedlings. Plant Physiology, v.114, n.2, p.695-704, 1997.

PUPPO, A.; DIMITRIJEVIC, L.; RIGAUD, J. Superoxide dismutase and catalase activities in purified Frankia vesicles. Physiologia Plantarum, v.77, n.3, p.308$311,1989$.

PÜTTER, J. Peroxidase. In BERGMEYER, H.U. (Ed.) Methods of enzymatic analysis. 2 ed. New York: Academic Press, 1974. v.2, p.567-1124,

RAO, M.V.; PALIYATH, G.; ORMROD, D.P. Ultraviolet-B and ozone-induced biochemical changes in antioxidant enzymes of Arabidopsis thaliana. Plant Physiology, v.110, n.1, p.125-136, 1996.

RICE-EVANS, C.A.; DIPLOCK, A.T.; SYMONS, M.C.R. Techniques in free radical research. New York: Elsevier, 1991. 291p. (Laboratory Techniques in Biochemistry and Molecular Biology, 22)

RUIZ-LOZANO, J.M.; AZCÓN, R.; PALMA, J.M. Superoxide dismutase activity in arbuscular mycorrhizal Lactıca sativa plants subjected to drought stress. New Phytologist, v.134, n.2, p.327-333, 1996.

RYALS, J.A.; NEUENSCHWANDER, U.H.; WILLITS, M.G.; MOLINA, A.; STEINER, H.Y.; HUNT, M.D. Systemic acquired resistance. The Plant Cell, v.8, n. 10, p.1809-1819, 1996.

SCANDALIOS, J.G. Response of plant antioxidant defense genes to environmental stress. Advances in Genetics, v.28, p.1-41, 1990.

SCANDALIOS, J.G. Oxygen stress and superoxide dismutases. Plant Physiology, v.101, n.1, p.7-12, 1993.

SCHWACKE, R.; HAGER, A. Fungal elicitors induce a transient release of active oxygen species from cultured spruce cells that is dependent on $\mathrm{Ca}^{2+}$ and proteinkinase activity. Planta, v.187, n. 1, p.136-141, 1992. 
SHARMA, Y.K. Structure and regulation of defense genes in bean. Austin, 1992. 107p. Thesis (Ph D) - University of Texas at Austin.

SIES, H. Strategies of antioxidant defense. European Journal of Biochemistry, v.215, n.2, p.213-219, 1993.

SLVEIRA, A.P.D. Micorrizas. In: CARDOSO, E.J.B.N.; TSAI, S.M.; NEVES, M.C.P. (Ed.) Microbiologia do solo. Campinas: Sociedade Brasileira de Ciência do Solo, 1992. p.257-282.

SIQUEIRA, J.O.; COLOZZI-FILHO, A. Micorrizas vesículo-arbusculares em mudas de cafeeiro II. Efeito do fósforo no estabelecimento e funcionamento da simbiose. Revista Brasileira de Ciência do solo, v.10, n.3, p.207-211, 1986.

SIQUEIRA, J.O.; FRANCO, A.A. Biotecnologia do solo. Fundamentos e perspectivas. Brasília: MEC/ABEAS; Lavras: ESAL/FAEPE, 1988. 236p.

SMITH, S.E.; SMITH, F.A. Structure and function of the interfaces in biotrophic symbiosis as they relate to nutrient transport. New Phytologist, v.114, n.1, p.1-38, 1990.

SPANU, P.; BONFANTE-FASOLO, P. Cell-wall-bound peroxidase activity in roots of mycorrhizal Allium porrum. New Phytologist, v.109, n.1, p.119-124, 1988.

SPANU, P.; BOLLER, T.; LUDWIG, A.; WIEMKEN, A.; FACCIO, A.; BONFÁNTEFASOLO, P. Chitinase in roots of mycorrhizal Allium porrum: regulation and localization. Planta, v. 177, n.4, p.447-455, 1989.

TENHAKEN, R.; LEVINE, A.; BRISSON, L.; DIXON, R.; LAMB, C. Function of the oxidative burst in hipersensitive disease resistance. Proceedings of the National Academy of Sciences USA, v.92, n.10, p.4158-4163, 1995.

VAN HUYSTEE, R.B. Some molecular aspects of plant peroxidase biosynthetic studies. Annual Review of Plant Physiology, v.38, p.205-217, 1987.

VANACKER, H.; CARVER, T.L.W.; FOYER, C.H. Pathogen-induced changes in the antioxidant status of the apoplast in barley leaves. Plant Physiology, v.117, n.3, p.1103-1114, 1998.

VIERHEILIG, H.; ALT, M.; MOHR, U.; BOLLER, T.; WIEMKEN, A. Ethylene biosynthesis and activities of chitinase and $\beta$-1,3-glucanase in the roots of host and non-host plants of vesicular-arbuscular mycorrhizal fungi after inoculation with Glomus mosseae. Journal of Plant Physiology. v.143, p.337-343, 1994. 
VOLPIN, H.; ELKIND, Y.; OKON, Y.; KAPULNIK, Y. A vesicular arbuscular mycorrhizal fungus (Glomus intraradix) induces a defense response in alfafa roots. Plant Physiology, v.104, n.2, p. 638-689, 1994.

WAGIH, E.E. Stress proteins and isosymology of acid phosphatase, esterase, and peroxidase in Phaseolus vulgaris following peanut mottle virus infection. Journal of Phytopathology, v.139, n.2, p.157-164, 1993

WALKER, C.; TRAPPE, J.M. Names and epiphets in the Glomales and Endogonales. Mycological Research, v.97, p.339-344, 1993.

WECKX, J.E.J.; CLIJTERS, H.M.M. Oxidative damage and defense mechanisms in primary leaves of Phaseolus vulgaris as a result of root assimilation of toxic amounts of copper. Physiologia Plantarum, v.96, n.3, p.506-512, 1996.

WILLIAMSON, J.D.; SCANDALIOS, J.G. Response of the maize catalases and superoxide dismutases to cercosporin-containing fungal extracts: the pattern of catalase response in scutella is stage specific. Physiologia Plantarum, v.88, n.1, p. $\$ 59-166,1993$.

WOODBURY, W.; SPENCER, A. K.; STAHMANN, M.A. An improved procedure using ferrycianide for detecting catalase isosymes. Analytical Biochemistry. v.44, n. 1, p.301-305, 1971.

WU, G.; SHORTT, B.J.; LAWRENCE, E.G.; LEVINE, E.B.; FITZSIMMONS, K.C.; SHAH, D.M. Disease resistance conferred by expression of a gene encoding $\mathrm{H}_{2} \mathrm{O}_{2}-$ generating glucose oxidase in transgenic potato plants. Plant Cell, v.7, n.9, p.13571468,1995 .

WU, G.; SHORTT, B.J.; LAWRENCE, J.L.; FITZSIMMONS, K.C.; LEVINE, E.B.; RASKIN, I.; SHAH, D.M. Activation of host defense mechanisms by elevated production of $\mathrm{H}_{2} \mathrm{O}_{2}$ in transgenic plants. Plant Physiology, v.115, n.2, p. 427-435, 1997.

YONG-MEI, B.; KENTON, P.; MUR, L.; DARBY, R.; DRAPER, J. Hydrogen peroxide does not function dowstream of salicylic acid in the induction of PR protein expression. Plant Journal, v. 8, n.2, p. 235-245, 1995. 